\title{
Associations among neighborhood poverty, perceived neighborhood environment, and depressed mood are mediated by physical activity, perceived individual control, and loneliness
}

\author{
Sarah D. Kowitt ${ }^{\mathrm{a}, \mathrm{b}, *}$, Allison E. Aiello ${ }^{\mathrm{c}, \mathrm{g}}$, Leigh F. Callahan ${ }^{\mathrm{c}, \mathrm{d}, \mathrm{e}}$, Edwin B. Fisher ${ }^{\mathrm{a}, \mathrm{f}}$, \\ Nisha C. Gottfredson ${ }^{\mathrm{a}}$, Joanne M. Jordan ${ }^{\text {c, d,e }}$, Kathryn E. Muessig ${ }^{\mathrm{a}}$ \\ ${ }^{a}$ Department of Health Behavior, Gillings School of Global Public Health, University of North Carolina at Chapel Hill, Chapel Hill, NC, 27599, USA \\ ${ }^{\mathrm{b}}$ Department of Family Medicine, School of Medicine, University of North Carolina at Chapel Hill, Chapel Hill, NC, 27599, USA \\ ${ }^{\mathrm{c}}$ Department of Epidemiology, Gillings School of Global Public Health, University of North Carolina at Chapel Hill, Chapel Hill, NC, 27599, USA \\ ${ }^{\mathrm{d}}$ Thurston Arthritis Research Center, University of North Carolina, 3300 Doc J. Thurston Bldg, CB\#7280, Chapel Hill, 27599-7280, NC, USA \\ e School of Medicine, University of North Carolina at Chapel Hill, Chapel Hill, NC, 27599, USA \\ ${ }^{\mathrm{f}}$ Peers for Progress, University of North Carolina at Chapel Hill, Chapel Hill, NC, 27599, USA \\ ${ }^{g}$ Carolina Population Center, University of North Carolina Chapel Hill, Chapel Hill, NC, 27599, USA
}

A R T I C L E I N F O

\section{Keywords:}

Depression

Neighborhoods

Mediation

Loneliness

Older adults

\begin{abstract}
A B S T R A C T
Few studies have documented the pathways through which individual level variables mediate the effects of neighborhoods on health. This study used structural equation modeling to examine if neighborhood characteristics are associated with depressive symptoms, and if so, what factors mediated these relationships. Crosssectional data came from a sample of mostly rural, older adults in North Carolina (n 1,558). Mediation analysis indicated that associations among neighborhood characteristics and depressive symptoms were mediated by loneliness (standardized indirect effect $0.19, \mathrm{p}<0.001$ ), physical activity (standardized indirect

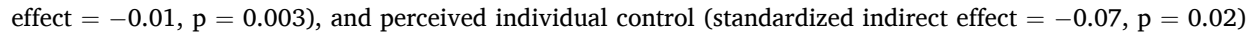
with loneliness emerging as the strongest mediator. Monitoring such individual mediators in formative and process evaluations may increase the precision of neighborhood-based interventions and policies.
\end{abstract}

\section{Introduction}

Neighborhoods influence health and wellbeing, but the mechanisms of these effects are not well understood. Taking depression as an example, while at least six systematic reviews in the past decade (Richardson et al., 2015; Kim, 2008; Mair et al., 2008; Evans, 2003; Truong and Ma, 2006; Gong et al., 2016) have examined if neighborhood features are associated with depression and/or mental health, few of the included studies examined how neighborhood characteristics are associated with outcomes. This stands in contrast to the number of theories and conceptual frameworks that have been developed to illustrate how neighborhoods affect health (see work on social determinants of health (Braveman et al., 2011), social disorganization theory (Shaw and McKay, 1996) and conceptual models from Diez Roux \& Mair (Diez
Roux et al., 2010), Brown et al. (Brown et al. (2004), Carpiano (2006), Blair et al. (2014), and Kawachi \& Berkman (Kawachi et al., 2014)). In these conceptual models, characteristics of the neighborhood economic environment (e.g., neighborhood poverty, disadvantage, or racial segregation) are thought to influence characteristics of the neighborhood physical environment (e.g., environmental exposures, food, physical activity, and recreation resources, services), and characteristics of the neighborhood social environment (e.g., safety, norms, cohesion, capital) (Diez Roux et al., 2010). In turn, characteristics of the neighborhood physical and social environments are then associated with health outcomes both directly and indirectly through various mediators, including but not limited to:

\footnotetext{
* Corresponding author. Department of Health Behavior, Gillings School of Global Public Health, University of North Carolina at Chapel Hill, Chapel Hill, NC, 27599, USA.

E-mail addresses: kowitt@unc.edu (S.D. Kowitt), aaiello@email.unc.edu (A.E. Aiello), leigh_callahan@med.unc.edu (L.F. Callahan), fishere@email.unc.edu (E.B. Fisher), gottfredson@unc.edu (N.C. Gottfredson), joanne_jordan@med.unc.edu (J.M. Jordan), kate_muessig@med.unc.edu (K.E. Muessig).
} 
(1) Psychosocial processes (e.g., social support, loneliness, stress, resiliency, sense of control, sense of fear and anxiety) (Diez Roux et al., 2010; Blair et al., 2014)

(2) Health behaviors, including physical activity (Braveman et al., 2011; Shaw and McKay, 1996; Diez Roux et al., 2010; Brown et al., 2004, 2007; Carpiano, 2006; Browning and Cagney, 2002)

(3) Access to resources, medical care, and quality of medical care (Braveman et al., 2011; Diez Roux et al., 2010; Brown et al., 2004, 2007)

Most of these conceptual models were built for general use, without regard to specific populations or settings. However, some research suggests that neighborhoods are particularly important for older adults since they 1) are less mobile than younger adults (Manini, 2013), which may make them more likely to rely on resources within their neighborhoods; 2) may lose social contacts as they age (Charles and Carstensen, 2010), thereby increasing the importance of social cohesion, and 3) may not leave their neighborhoods as much as younger adults who may be working or have other obligations (Glass et al., 2003). In addition, most older adults (nearly 80\%) own their homes (Pew Research Center, 2017) and have lived in their neighborhoods for a number of years, thereby increasing aggregate exposure to residential neighborhood effects. The number and magnitude of these factors suggest that older adults may have a heightened vulnerability to certain neighborhood features and make research on neighborhoods and older adults especially useful (Glass et al., 2003; Berkman and Glass, 2000).

Previous research among older adults has especially highlighted the importance of perceptions of neighborhood environment for health and wellbeing. For instance, the causal model of neighborhood effects on aging (Glass et al., 2003), which is an extension of the ecological model of aging developed by Lawton et al. (Lawton and Nahemow, 1973), highlights the importance of social integration (including social cohesion and safety), physical aspects of place (e.g., noise, deterioration), and available services and resources (including access to resources for physical activity, transportation, shops), in addition to socioeconomic conditions. In line with this conceptual model, research has shown that the negative effect of perceived safety on physical activity is particularly pronounced among older adults (Glass et al., 2003), that perceived access to resources (e.g., perceiving there to be attractive features in the nearby environment for outdoor activities, or perceiving nature to be a facilitator of exercise) is associated with better mobility of older adults (Eronen et al., 2014), especially older adults with difficulties in walking (Keskinen et al., 2018), and that low perceived social cohesion is associated with decreased social participation (Latham and Clarke, 2018). While understudied, researchers suggest that greater social cohesion in a neighborhood can lead residents to be more willing to help one another, make residents feel more secure, increase opportunities for social activity and engagement, and increase opportunities for residents to organize for what they need (Glass et al., 2003).

Moreover, most studies investigating neighborhoods and health of older adults have been conducted in urban environments, with few studies examining whether associations between neighborhoods and health extend to rural and suburban areas (Glass et al., 2003). Studying how neighborhoods relate to the health and wellbeing of older adults in rural neighborhoods may be important for two reasons. First, the concept of a "neighborhood" may be more difficult to define in rural areas (De Marco and De Marco, 2010), and so, we need empirical research documenting what neighborhood characteristics, if any, are important for older adults in non-urban areas. Second, older adults in rural areas may be even more vulnerable than those in urban areas, given disparities in health between rural and urban environments (Singh and Siahpush, 2014) and that sparseness of rural areas may make it more difficult for older adults to access resources and social connections. Therefore, documenting the influence of neighborhoods on older adults' health in rural areas may guide needed interventions to improve health.

Guided by previous research, we hypothesized that-among older adults living in primarily rural neighborhoods-four neighborhood characteristics (i.e., poverty, perceived social cohesion, perceived resources for physical activity, and perceived safety) would be associated with depressive symptoms via effects on physical activity, loneliness, and perceived individual control. An illustration of these pathways can be seen in Fig. 1. We focused on depressive symptoms as our outcome given that depression is a major public health problem (Greenberg et al., 2015), particularly for older adults (Chapman and Perry, 2008), the leading cause of disability worldwide (Friedrich, 2017), and a well-studied outcome for neighborhood research (Richardson et al., 2015; Kim, 2008; Mair et al., 2008; Evans, 2003; Truong and Ma, 2006; Gong et al., 2016).

\section{Methods}

\subsection{Participants and procedures}

Data for this study come from a population-based prospective cohort of knee and hip osteoarthritis (OA) among African American and White individuals (the Johnston County Osteoarthritis Project, "JoCo OA") (Jordan, 2015). Although the parent study was designed to capture OA prevalence and risk factors, we used the data to examine how neighborhood characteristics were associated with wellbeing among a large sample of older adults. Participants were not selected on the basis of whether they did or did not have any specific health condition, including arthritis. Recruitment occurred in Johnston County, North Carolina (NC), which at the time of this study, was classified as a mostly rural county (U.S. Census Bureau, 2010). Details on the study design, data collection procedures, and study population are detailed in previous publications (Jordan, 2015). In brief, the study was designed to be representative of civilian, non-institutionalized African Americans and White individuals over the age of 45 who resided in one of six towns or townships in Johnston County, NC for at least one year, were living in the county at the time of study enrollment, and physically and mentally capable of completing the study protocol. Data were collected in-person. All participants provided informed written consent at the time of recruitment. The study was approved by the Institutional Review Boards of the University of North Carolina Schools of Medicine and Public Health and the Centers for Disease Control and Prevention. The analytical sample for this study uses the T2: 2006-2011 cohort of adults. We chose this wave of data collection since it was the only wave in which neighborhood characteristics were measured.

\subsection{Measures}

A list of all measures used in this study can be found in the appendix (Table A).

Outcome. We used the Center for Epidemiological Studies Depression (CES-D) scale to assess depressive symptoms. The CES-D is one of the most widely used scales to assess levels of depressive symptomology (Radloff, 1991). Developed in 1977, the CES-D was intended to assess epidemiology of depression in the general population, rather than diagnosis at clinical intake (Radloff, 1991). While items were chosen from previously validated depression scales and based on symptoms of depression in clinical cases, the CES-D was not designed to reflect diagnostic criteria of depression at the time of its development (Radloff, 1991). In contrast to other widely used measures, such as the Beck Depression Inventory, the CES-D focuses more on affective aspects of depression, rather than depression cognitions (Muñoz and Ying, 2002).

The CES-D contains 20 items that assess whether symptoms had occurred in the week prior to the interview. Response options range from 0 to 3, which refer to frequency of the symptoms (i.e., "rarely or none of the time" to "all of the time"). The CES-D was originally posited to have a four-factor structure composed of depressed affect, positive affect, somatic activity, and interpersonal issues (Radloff, 1991). However, more than 20 alternative factor structures-including a 


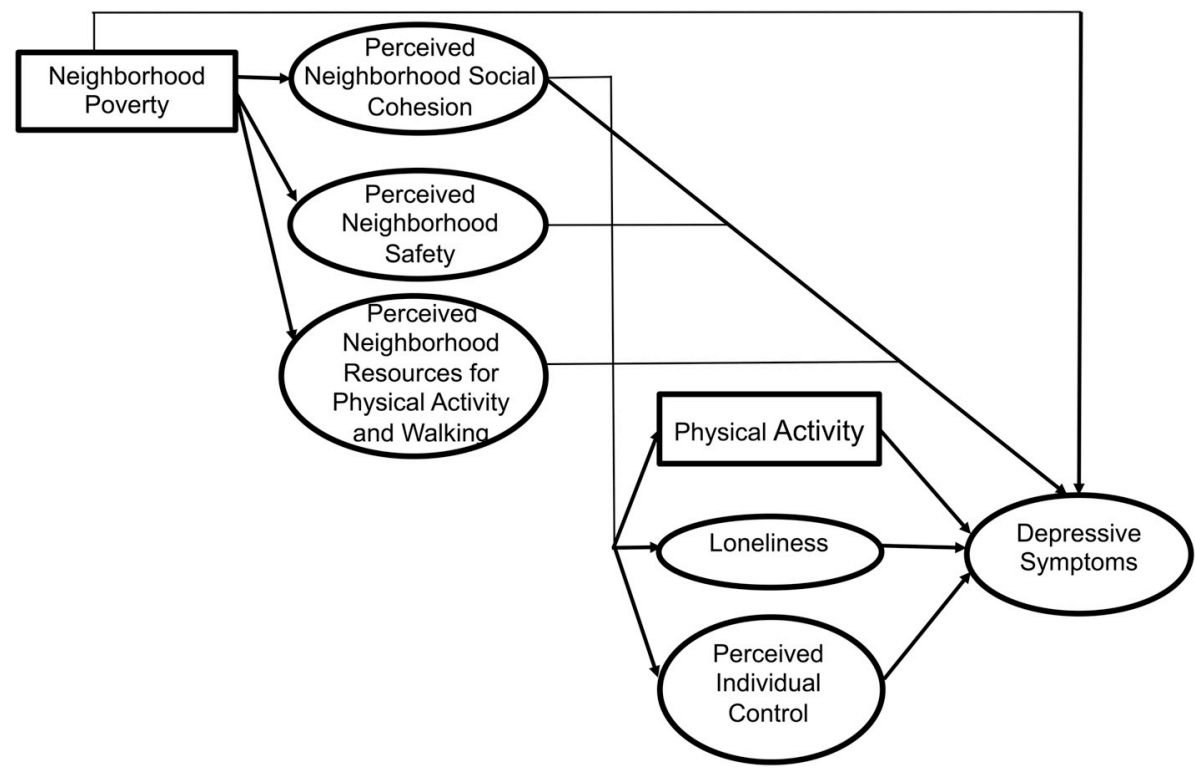

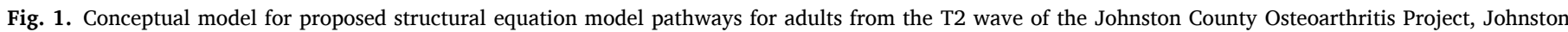
County, North Carolina, 2006-2011.

Note: Ovals denote latent variables; measurement model and control variables not shown for simplicity.

unidimensional factor structure (Edwards et al., 2010) — have been reported (Carleton et al., 2013). In practice, many researchers (including Radloff, the original developer of the CES-D) report a total score, thereby treating the measure as unidimensional (Edwards et al., 2010). We therefore analyzed depressive symptoms as a unidimensional latent variable. Although a cut-off point of 16 (total possible score range 0-60) has been used in previous research to indicate risk for moderate or severe depression (Weissman et al., 1977), we conceptualized and analyzed CES-D scores as a continuum in order to maximize sensitivity of the measure. For consistency, we refer to the latent variable comprised of CES-D items as "depressive symptoms" throughout this manuscript.

Neighborhood characteristics. We measured four neighborhood characteristics.

Neighborhood poverty. We defined neighborhood poverty as the percentage of households with income below the poverty line within a census block group. We compiled these data from the 2010 U.S. Census, that bounded the time in which T2 data were gathered, 2006-2011. We used census block groups as the unit of analysis, since they are the smallest administrative boundary from the census that includes economic data. Census block groups generally contain between 600 and 3,000 people (U.S. Census Bureau, 2017).

Perceived neighborhood social cohesion. We measured perceived neighborhood social cohesion using 5-item measure of Social Cohesion and Trust of Sampson and colleagues (Sampson et al., 1997). An example item is: "people around here are willing to help their neighbors" (1 strongly agree, 5 strongly disagree). Previous studies have found high reliability for this scale (Cronbach's alpha of 0.82 and 0.86 at two different time points) and consistency over time (test-retest intra class correlation, ICC: 0.90; 95\% CI: 0.84, 0.94) (Echeverria et al., 2004). Supporting validity, the scale has also been used in a variety of research studies assessing social cohesion/social capital (Mair et al., 2008, 2009; Martin et al., 2010).

Perceived neighborhood resources for physical activity and walking. We measured perceived neighborhood resources for physical activity and walking using 11 items from the Walking and Exercise Environment scale (Echeverria et al., 2004). This scale assesses opportunities for exercise in individuals' neighborhoods. An example item is: "my neighborhood offers many opportunities to be physically active" (1 strongly agree, 5 strongly disagree). Previous studies have shown this scale to have high reliability and consistency over time (test-retest ICC: 0.88; 95\% CI: 0.79, 0.93) (Echeverria et al., 2004).

Perceived neighborhood safety. We measured perceived neighborhood safety with three items. An example item is: "I feel safe walking in my neighborhood during the evening" ( $1 \quad$ strongly agree, 5 strongly disagree). Previous studies have demonstrated these items to be reliable and consistent over time (test-retest ICC: 0.80 ; 95\% CI: 0.67 , 0.88) (Echeverria et al., 2004).

Mediators. We selected three mediators based on their importance in previous research.

Physical activity. We assessed physical activity using items from the 2001-2009 Behavioral Risk Factor Surveillance System (BRFSS) (Centers for Disease Control and Prevention, 2016), which classifies individuals as inactive, insufficiently active, or active. Following guidelines for use of the BRFSS physical activity questions(42), to be classified as meeting recommended goals for moderate activity, a respondent needed to report 5 or more days of moderate activity with 30 or more minutes per day. To be classified as meeting recommended goals for vigorous activity, a respondent needed to report 3 or more days of vigorous activity with 20 or more minutes per day. An individual who met the moderate goal, the vigorous goal, or both was classified as "active" while an individual who reported some moderate activity, vigorous activity, or both but did not meet the goals for either moderate or vigorous activity was classified as "insufficiently active." Otherwise, individuals were classified as "inactive."

Loneliness. We assessed loneliness using four items from the Strong Ties scale (Dean and Lin, 1977), which asks participants: "How often are you bothered by not ..." 1) "having a close companion?", 2) "seeing people you feel close to?“, 3) "having enough close friends?", and 4) "having someone who shows you love and affection?" (1 all of the time, 5 never). Items were reverse coded so that higher scores indicate more loneliness. These items have been used in previous research (O'Connor and Fitzpatrick, 2017; De Vellis et al., 1986; Coty and Wallston, 2010; Brown et al., 1989) and have been found to be reliable (Cronbach's alpha 0.89) (De Vellis et al., 1986). Additionally, moderate correlations with other constructs, such as social contacts (De Vellis et al., 1986) and depressive symptoms (Coty and Wallston, 2010), suggest these items are valid. 
Perceived individual control. To assess perceived individual control, we used two items from Israel et al.'s Perceived Control Scale (Israel et al., 1994). These items were: "I have control over the decisions that affect my life" and "I am satisfied with the amount of control I have over decisions that affect my life" (1 strongly agree to 5 strongly disagree). We reverse-coded items so that higher scores indicate more control. These items have been used in previous research studies and found to be reliable (Cronbach's alpha 0.83) (Taylor et al., 2012, 2017; Kim et al., 2016).

Control variables. Control variables assessed included standard demographic variables as well as health-related variables that could independently be associated with depressive symptoms and neighborhood context. Specifically, we assessed race/ethnicity (White or Black/ African American), education (categorized as less than high school or high school or greater), BMI (based on measured height and weight, a continuous variable), gender (male or female), age (a continuous variable), health insurance status (categorized as public insurance, private insurance, or none), and number of comorbidities (assessed using a disease inventory index). We also assessed knee OA status as a control variable using radiography and the Kellgren and Lawrence (KL) grade, which scores OA severity on a scale of 0-4 (Neogi and Zhang, 2013). We classified individuals with scores of $2-4$ in at least one knee as having knee OA. Otherwise, we classified individuals as not having knee OA.

\subsection{Data analysis}

Descriptive statistics. Descriptive statistics included means, standard deviations, and frequencies of all identified demographic variables, neighborhood variables, and depressive symptoms. Bivariate correlation analyses were used to assess relationships among neighborhood variables and depressive symptoms. We conducted descriptive statistics using SAS version 9.4 survey procedures (SAS Inc., Cary, NC, USA).

Confirmatory factor analysis and structural equation modeling. To examine how neighborhood characteristics were related to depressive symptoms through the proposed mediators, we used structural equation modeling (SEM) (Bowen and Guo, 2011). We chose to use SEM since we were testing complex mediation models (multiple sequential mediators), had several hypothesized latent variables, and needed to control for clustering of observations within neighborhoods. Prior to using SEM, we verified that there were no significant interactions among any of the exposures and mediators.

Using MPlus version 7, we followed a two-step structural equation modeling approach to establish the quality of the measurement model using confirmatory factor analysis (CFA) and test the full general SEM (Anderson and Gerbing, 1988). We first used CFA to evaluate the fit of six latent variables: 1) perceived neighborhood social cohesion, 2) perceived neighborhood resources for physical activity and walking, 3) perceived neighborhood safety, 4) loneliness, 5) perceived individual control, and 6) depressive symptoms. These variables were specified as latent variables because they represent unobservable (i.e., latent) constructs and they were measured using multiple items (combined into scales), which thereby makes CFA appropriate. We examined neighborhood poverty and physical activity as observed variables. We entered the remaining control variables into the models as observed variables.

After determining adequate fit of the measurement models using CFA and making any necessary modifications, we assessed the fit of the structural model controlling for clustering at the neighborhood census block group level (using type complex), which adjusts standard errors using an empirical correction. As seen in Fig. 1, our SEM contains three main pathways: 1) the pathway from neighborhood poverty to perceived neighborhood environment, 2) the pathway from perceived neighborhood environment to the proposed mediators, and 3) the pathway from the proposed mediators to depressive symptoms.

In SEM, indirect effects are calculated as the product of the pathway from independent variable to the mediator (a path) and the pathway from the mediator to the outcome (b path) (Gunzler et al., 2013). In contrast to estimating effects in separate regression models, SEM simultaneously estimates direct and indirect effects (Fairchild and McDaniel, 2017). Also in SEM, indirect effects are tested using bootstrapping, which involves taking multiple repeated samples from the dataset. For each bootstrapped sample, the model is refit and estimates for all the parameters (including path coefficients and standard errors) are obtained. From these values, confidence intervals are calculated.

To determine the fit of the measurement model and SEM, we used a priori, well-established criteria, including the chi-square test (p-value should be $>0.05$; however, model fit can still be adequate if this p-value is $<0.05$ since chi-square is dependent on sample size (Joreskog, 1969)); the Comparative Fit Index (CFI) and Tucker-Lewis Index (TLI) (CFI, TLI should be $>0.95$ (Tucker and Lewis, 1973; Bentler, 1990)); the root mean square error of approximation (RMSEA, should be $<0.08$ (Steiger and Lind, 1980; Kline, 2011)); and standardized factor loadings (should be $>0.30$ (Cabrera-Nguyen, 2010)). The model illustrated in Fig. 1 was tested. Given that all manifest variables were ordinal (measured on a 1-5 scale), we used weighted least squares means and variance adjusted (WLSMV) estimation, which is appropriate for data with non-normal distributions (Bowen and Guo, 2011). Although parameter estimates are more difficult to estimate using WLSMV because a probit model is used, previous researchers have used WLSMV to analyze mediation (Mason et al., 2009; Sawatzky et al., 2010; Weden et al., 2008) and this approach avoids bias associated with the inclusion of categorical indicators. Our sample included participants with full data on covariates. In our models, 139 participants (approximately $8.2 \%$ of the sample) were missing some of the observed exogenous variables (i.e., control variables) and excluded by MPlus. For all analyses, we set critical $\alpha$ 0.05 and used 2-tailed statistical tests.

Sensitivity Analyses. We conducted two sensitivity analyses. In the first, we analyzed separately somatic and non-somatic depressive symptoms on the CES-D, since it is possible that they would be differentially associated with neighborhood characteristics and mediators. Somatic symptoms included items 1, 2, 5, 7, 11, and 20 from the CES-D and referred to whether individuals were bothered by things, had a poor appetite, had trouble keeping their mind on what they were doing, felt that everything was an effort, had restless sleep, and could not get going (Carleton et al., 2013). Remaining items assessed non-somatic symptoms related to affect (e.g., "I felt sad"), anhedonia (e.g., "I enjoyed life"), and interpersonal concerns (e.g., "People wer unfriendly"). Second, sensitivity analyses evaluated whether relationships remained apparent when the sample was confined only to those with chronic conditions to determine whether relationships between neighborhood context and depressive symptoms varied by chronic disease status (see Appendix Table A for the list of included chronic conditions). Third, sensitivity analyses evaluated whether relationships remained apparent when the sample was confined only to those with OA (knee or hip) plus another chronic condition.

\section{Results}

\subsection{Descriptive statistics}

Details on the demographic characteristics of participants are presented in Table 1. The sample was composed of adults who were on average 68.1 years old (SD: 9.1). Participants were diverse, with a substantial number of African Americans (31.2\%) and individuals without a high school degree (21.8\%). Almost half of participants $(44.5 \%)$ had radiographic knee OA and on average, had 1.7 other comorbidities. Overall, $90.9 \%$ of the sample reported at least one chronic condition. Additionally, participants reported few depressive symptoms (mean CES-D score: 6.6, SD: 7.5, possible range: 0-60), although $11.4 \%$ had scores at or above 16 suggestive of moderate or severe depression. 
Table 1

Participant characteristics of adults from the T2 wave of the Johnston County Osteoarthritis Project, Johnston County, North Carolina, 2006-2011, n 1697.

\begin{tabular}{|c|c|}
\hline Characteristic & $\begin{array}{l}\mathrm{N}(\%) \text { or mean } \\
\text { (SD) }\end{array}$ \\
\hline \multicolumn{2}{|l|}{ Race } \\
\hline White & $1167(68.8)$ \\
\hline African American or Black & $530(31.2)$ \\
\hline \multicolumn{2}{|l|}{ Gender } \\
\hline Male & $552(32.5)$ \\
\hline Female & $1145(67.5)$ \\
\hline Age (range 50-95), mean (SD) & $68.1(9.1)$ \\
\hline BMI (range 12.6-78.1), mean (SD) & $31.5(7.2)$ \\
\hline \multicolumn{2}{|l|}{ Education } \\
\hline High school or greater & $1297(78.2)$ \\
\hline Less than high school & $362(21.8)$ \\
\hline \multicolumn{2}{|l|}{ Health insurance } \\
\hline Public & $1176(69.3)$ \\
\hline Private & $412(24.3)$ \\
\hline None & $109(6.4)$ \\
\hline Number of comorbidities (range $0-11)^{a}$ & $1.7(1.3)$ \\
\hline \multicolumn{2}{|l|}{ Knee OA ${ }^{a}$} \\
\hline No & $910(55.5)$ \\
\hline Yes & 729 (44.5) \\
\hline Neighborhood poverty (range $0-44$ ), mean (SD) & $16.7(10.3)$ \\
\hline Perceived neighborhood social cohesion (range 5-25), mean (SD) & $18.9(3.6)$ \\
\hline $\begin{array}{l}\text { Perceived neighborhood resources for physical activity and } \\
\text { walking (range 11-55), mean (SD) }\end{array}$ & $35.9(6.2)$ \\
\hline Perceived neighborhood safety (range 3-15) & $11.0(2.3)$ \\
\hline Loneliness (range 4-20), mean (SD) & $6.2(2.7)$ \\
\hline Perceived individual control (range 2-10), mean (SD) & $8.0(1.5)$ \\
\hline \multicolumn{2}{|l|}{ Physical activity } \\
\hline Inactive & $484(28.7)$ \\
\hline Insufficiently active & $627(37.2)$ \\
\hline Sufficiently active & $573(34.0)$ \\
\hline Depressive symptoms (range 0-60), mean (SD) & $6.6(7.5)$ \\
\hline
\end{tabular}

a $91 \%$ of the sample had at least one chronic disease defined using a disease inventory index and radiographic assessments of knee OA. $52 \%$ of the sample had OA (knee or hip) plus another chronic disease.

\subsection{Confirmatory factor analysis}

The measurement model with no modifications had a moderate fit to the data (See AppendixTable B). Two latent variables had poor initial fit: the measure for perceived neighborhood resources for physical activity and walking and that for loneliness. After reviewing correlation matrices for the 11 items making up the factor for neighborhood resources for physical activity and walking, we included 4 items in the revised model ("My neighborhood offers many opportunities to be physically active," "It is pleasant to walk in my neighborhood," "There are enough trees in my neighborhood to provide shade," and "In my neighborhood, the streets or sidewalks are in good condition"). We chose these items based on both empirical (inter-item correlations $>0.40$ ) and theoretical evidence from previous literature, suggesting streets, shade, and neighborhood aesthetics are important domains for walkability in rural neighborhoods (Kegler et al., 2015). Loneliness was left unmodified from the widely used version we employed (Dean and Lin, 1977). Although the RMSEA value $(0.12 ; 95 \%$ CI: $0.19,0.15)$ was above the desired 0.06 cut-off (Steiger and Lind, 1980; Kline, 2011), the model demonstrated adequate fit based on the other indices and modifications would not have been theoretically or empirically based.

\subsection{Bivariate correlations}

Bivariate analyses revealed significant relationships among most latent and observed variables in the hypothesized directions (Table 2). Correlations of neighborhood poverty with other neighborhood variables ranged from 0.11 to 0.26 (all p-values $<0.05$ ), while correlations among perceived neighborhood social cohesion, perceived neighborhood resources for physical activity and walking, and perceived neighborhood safety were moderate to high, ranging from 0.66 to 0.75 (all p-values $<0.001$ ). These three neighborhood characteristics were all significantly associated with the three selected mediators (physical activity, loneliness, and perceived individual control, all p-values $<0.001$ ). Finally, depressive symptoms were moderately associated with all variables, except for neighborhood poverty for which there was a weak, but still statistically significant association ( $\mathrm{r} \quad 0.08, \mathrm{p} \quad 0.03$ ).

\subsection{Structural equation model}

The initial hypothesized structural equation model had a relatively good fit to the data, but several of the associations among perceived neighborhood social cohesion, perceived neighborhood resources for physical activity and walking, perceived neighborhood safety, and the proposed mediators were not in the expected direction based on bivariate correlational results. We hypothesized that this was due to high correlations among the three perceived neighborhood characteristics (ranging from 0.66 to 0.75 ). When multicollinearity is present, the introduction of additional predictors into the model can diminish the regression coefficient and significance of a predictor, and the regression coefficient can even reverse in sign (Pedhazur, 1997). We therefore fit a model with a higher order factor (labeled "perceived neighborhood environment"), which was comprised of these three neighborhood characteristics (social cohesion, resources for physical activity/walking, safety) and only specified pathways that were significant in the bivariate correlations at $\mathrm{p}<0.05$.

Table 2

Correlation matrix of observed and latent variables for adults from the T2 wave of the Johnston County Osteoarthritis Project, Johnston County, North Carolina, 2006-2011, n 1697.

\begin{tabular}{|c|c|c|c|c|c|c|c|c|}
\hline & $\begin{array}{l}\text { 1.Neighborhood } \\
\text { poverty }\end{array}$ & $\begin{array}{l}\text { 2.Perceived } \\
\text { neighborhood social } \\
\text { cohesion }\end{array}$ & $\begin{array}{l}\text { 3.Perceived neighborhood } \\
\text { resources for physical activity } \\
\text { and walking }\end{array}$ & $\begin{array}{l}\text { 4.Perceived } \\
\text { neighborhood } \\
\text { safety }\end{array}$ & $\begin{array}{l}\text { 5.Physical } \\
\text { activity }\end{array}$ & $\begin{array}{l}6 . \\
\text { Loneliness }\end{array}$ & $\begin{array}{l}\text { 7.Perceived } \\
\text { individual } \\
\text { control }\end{array}$ & $\begin{array}{l}\text { 8.Depressive } \\
\text { symptoms }\end{array}$ \\
\hline 1 & - & $-0.18^{* * *}$ & $-0.11^{*}$ & $-0.26^{* * * *}$ & $-0.14^{* * *}$ & 0.03 & 0.01 & $0.08^{*}$ \\
\hline 3 & & & - & $0.68^{* * *}$ & $0.13^{* * *}$ & $-0.34^{* * *}$ & $0.65 * * *$ & $-0.32^{* * *}$ \\
\hline 4 & & & & - & $0.14 * * *$ & $-0.28^{* * *}$ & $0.35^{* * * *}$ & $-0.26^{* * *}$ \\
\hline 5 & & & & & - & $-0.17^{* * *}$ & 0.06 & $-0.22^{* * *}$ \\
\hline 6 & & & & & & - & $-0.36^{* * *}$ & $0.56^{* * *}$ \\
\hline
\end{tabular}

Note, in final structural models, a higher order factor comprised of perceived neighborhood social cohesion, perceived neighborhood resources for physical activity and walking and perceived neighborhood safety was modeled. Correlations of this factor (perceived neighborhood environment) with poverty were $0.20^{* * *}$, with perceived individual control were $0.58^{* * *}$, with physical activity were $0.16^{* * *}$, and with loneliness were $0.39^{* * * *}$ and with depressive symptoms were $0.35 . * * *$. Boldface denotes significance at $\mathrm{p}<0.05$.

$* \mathrm{p}<0.05, * * \mathrm{p}<0.01, * * * \mathrm{p}<0.001$. 
Table 3

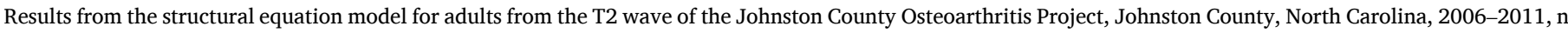
1558.

\begin{tabular}{|c|c|c|c|c|c|c|c|c|c|c|}
\hline \multirow{3}{*}{$\begin{array}{l}\text { Exogenous variables } \\
\text { Poverty }\end{array}$} & \multicolumn{10}{|c|}{ Endogenous variables } \\
\hline & \multicolumn{2}{|c|}{ Perceived neighborhood environment } & \multicolumn{2}{|c|}{ Physical activity } & \multicolumn{2}{|c|}{ Loneliness } & \multicolumn{2}{|c|}{ Perceived individual control } & \multicolumn{2}{|c|}{ Depressive symptoms } \\
\hline & $\mathrm{B}$ & $0.16^{* * *}$ & B & $0.06^{*}$ & - & & - & & $\mathrm{B}$ & 0.03 \\
\hline Perceived neighborhood environment & - & & B & $0.09 * *$ & B & $0.41^{* * *}$ & $\mathrm{~B}$ & $0.61 * * *$ & B & 0.001 \\
\hline Physical activity & - & & - & & - & & - & & B & $0.13^{* * *}$ \\
\hline Loneliness & - & & - & & - & & - & & $\mathrm{B}$ & $0.47^{* * *}$ \\
\hline Perceived individual control & & & & & & & - & & $\mathrm{B}$ & $0.12 *$ \\
\hline
\end{tabular}

Notes.

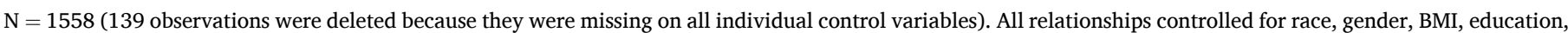

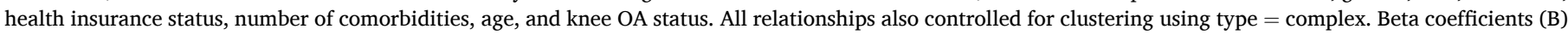
are standardized.

$* \mathrm{p}<0.05, * * \mathrm{p}<0.01, * * * \mathrm{p}<0.001$.

Model Fit.

Chi-Square value (p-value): 1724.40, p < 0.001; RMSEA: 0.02 (95\% CI: 0.02, 0.02); CFI: 0.96; TLI: 0.96.

Indirect Effects.

Perceived neighborhood environment $\rightarrow$ Physical activity $\rightarrow$ Depressive symptoms: B $\quad 0.01$ (95\% CI: $0.02, \quad 0.004), p \quad 0.003$.

Perceived neighborhood environment $\rightarrow$ Loneliness $\rightarrow$ Depressive symptoms: B $\quad 0.19$ (95\% CI: $0.23, \quad 0.16$ ), p $<0.001$.

Perceived neighborhood environment $\rightarrow$ Perceived individual control $\rightarrow$ Depressive symptoms: B $\quad 0.07$ (95\% CI: $0.13, \quad 0.01$ ), p $\quad 0.02$.

Poverty $\rightarrow$ physical activity $\rightarrow$ depressive symptoms: B $\quad 0.008$ (95\% CI: $0.000,0.02), p \quad 0.06$.

Poverty $\rightarrow$ perceived neighborhood environment $\rightarrow$ depressive symptoms: B $\quad 0.000$ (95\% CI: $0.02,0.02), p \quad 0.98$.

Poverty $\rightarrow$ perceived neighborhood environment $\rightarrow$ Physical activity ê Depressive symptoms: B $\quad 0.002$ (95\% CI: $0.000,0.003)$, p $\quad 0.01$.

Poverty $\rightarrow$ perceived neighborhood environment $\rightarrow$ loneliness $\rightarrow$ depressive symptoms: B $\quad 0.03$ (95\% CI: 0.02, 0.05), p $<0.001$.

Poverty $\rightarrow$ perceived neighborhood environment $\rightarrow$ perceived individual control $\rightarrow$ depressive symptoms: B $\quad 0.01$ (95\% CI: $0.001,0.02$ ), p $\quad 0.03$.

Poverty $\rightarrow$ perceived neighborhood environment $\rightarrow$ Physical activity: B $\quad 0.02$ (95\% CI: $0.03, \quad 0.004), p \quad 0.009$.

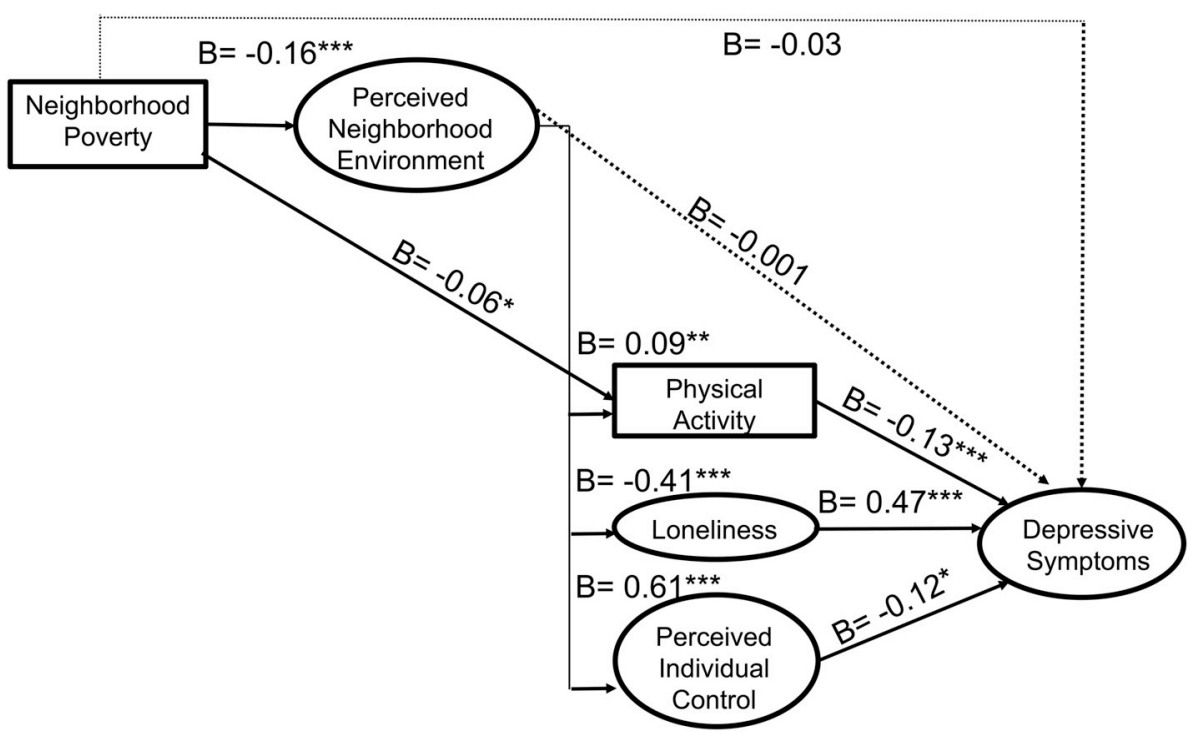

Fig. 2. Final conceptual model with direction and significance of parameter estimates for adults from the T2 wave of the Johnston County Osteoarthritis Project, Johnston County, North Carolina, 2006-2011, n 1558.

Notes: Dashed arrows indicate a non-significant pathway. All parameter estimates can be seen in Table 3. Circles denote latent variables; measurement model and control variables not shown for simplicity. Model adjusts for: race, gender, BMI, education, health insurance status, number of comorbidities, age, knee OA status, and clustering within neighborhoods. Chi-Square (p-value): 1724.40, $\mathrm{p}<0.001$ ); RMSEA: 0.02 (95\% CI: 0.02, 0.02); CFI: 0.96; TLI: 0.96.*p < $0.05 ; * * \mathrm{p}<0.01 ; * * * \mathrm{p}<0.001$

Results from the structural equation model can be seen in Table 3 and are displayed visually in Fig. 2. We found the model represented in Fig. 1 demonstrated adequate fit with respect to the following metrics: RMSEA 0.02 (95\% CI: 0.02, 0.02), CFI $\quad 0.96$, and TLI $\quad 0.96$. We selected this model as the final model.

We found neighborhood poverty was significantly negatively associated with perceived neighborhood environment (B $0.16, \mathrm{p}<$ 0.001 ) and physical activity (B $0.06, \mathrm{p} 0.04$ ), but not with depressive symptoms. In turn, perceived neighborhood environment was significantly associated with increased physical activity (B 0.09, $\mathrm{p} \quad$ 0.005), less loneliness (B $0.41, \mathrm{p}<0.001$ ), and increased perceived individual control ( $\mathrm{B} \quad 0.61, \mathrm{p}<0.001$ ), but not depressive symptoms (B $\quad 0.001, p \quad 0.98)$, despite their significance in bivariate correlations. All three mediators were significantly associated with depressive symptoms in the expected directions (physical activity and depressive symptoms: $\mathrm{B} \quad 0.13, \mathrm{p}<0.001$; loneliness and depressive symptoms: $\mathrm{B} \quad 0.47, \mathrm{p}<0.001$; and perceived individual control and depressive symptoms: $\mathrm{B} \quad 0.12, \mathrm{p} \quad 0.01$ ).

In addition, we observed a number of indirect effects. The hypothesized pathways from perceived neighborhood environment to depressive symptoms through the proposed mediators were all significant (standardized beta coefficients ranging from B $\quad 0.01$ to B $\quad 0.19$, pvalues $<0.05)$. Specifically, the indirect effect for perceived neighborhood environment on depressive symptoms through loneliness was B

0.19; 95\% CI: $0.23,0.16 ; \mathrm{p}<0.001$; the indirect effect through perceived individual control was B $\quad 0.07 ; 95 \%$ CI: $0.13,0.01 ; \mathrm{p}$ 
0.02; and the indirect effect through physical activity was B 0.01 ; 95\% CI: $0.02, \quad 0.004 ; p \quad 0.003$. Loneliness emerged as the strongest of the three mediators, as demonstrated through the non-overlapping $95 \%$ confidence intervals of the indirect effects.

In addition, poverty was significantly associated with depressive symptoms through physical activity and perceived neighborhood environment (B 0.002, p 0.01), loneliness and perceived neighborhood environment (B $0.03, \mathrm{p}<0.001$ ), and perceived individual control and perceived neighborhood environment ( $B \quad 0.01, p \quad 0.03$ ). Finally, poverty was significantly associated with physical activity through perceived neighborhood environment (B $\quad 0.02$, p 0.009).

Overall, all variables (neighborhood and control) explained $42 \%$ of the variance in depressive symptoms, $20 \%$ of the variance in loneliness, $37 \%$ of the variance in perceived individual control, and $13 \%$ of the variance in physical activity. Alone (including direct and indirect effects), neighborhood variables explained $12 \%$ of the variance in depressive symptoms, $15 \%$ of the variance in loneliness, $37 \%$ of the variance in perceived individual control, and $4 \%$ of the variance in physical activity.

\subsection{Sensitivity analysis}

Results from sensitivity analyses can be seen in the Appendix (Tables C, D, and E). When analyzing somatic and non-somatic depressive symptoms separately, all paths noted above were confirmed, with the exception that perceived individual control no longer mediated the effects of perceived neighborhood characteristics on somatic depressive symptoms (B $\quad 0.05, p \quad 0.06$ ) (Table C). Perceived individual control did, however, mediate the effects of perceived neighborhood characteristics on non-somatic depressive symptoms (B $\quad 0.08, p \quad 0.02$ ). In addition, we found that results did not change when only including adults with at least one chronic disease (Table D). However, when only including adults with OA (knee or hip) and another chronic disease, we found that perceived individual control was no longer associated with depressive symptoms (B $\quad 0.07, \mathrm{p} \quad 0.14$ ) and perceived neighborhood environment was no longer associated with physical activity (B 0.05, p 0.20) (Table E). Accordingly, physical activity and perceived individual control no longer mediated the effects of perceived neighborhood environment on depressive symptoms and the only significant mediator was loneliness (B $0.052, \mathrm{p}<0.001$ ).

\section{Discussion}

Among this sample of older adults- $91 \%$ of whom reported having at least one chronic condition - several neighborhood characteristics were associated with depressive symptoms. Within this pattern of results, two interesting findings were observed. First, neighborhood factors were strongly associated with depressive symptoms and this relationship was mediated by individual-level variables. This observation suggests that both individual-level and neighborhood-level characteristics may be important for future interventions looking to improve mental health outcomes. These findings also suggest that aging in place interventions, in particular, could focus attention on how neighborhood environment could be improved, in addition to making modifications to older adults' home environments. Second, we found that loneliness emerged as the strongest mediator of neighborhood characteristics on depressive symptoms. These findings have a number of important implications for public health practice and research, as discussed below.

Little research has examined how neighborhood characteristics are associated with health. In this study, we found three variables completely mediated the effects of perceived neighborhood environment on depressive symptoms. These results suggest the importance of these three variables-physical activity, loneliness, and perceived individual control—as behavioral and psychosocial mediators of the effects of neighborhood factors on depression. Additionally, we found that physical activity, loneliness, and perceived individual control mediated the effects of the perceived neighborhood environment on depressive symptoms and that when taking these indirect effects into account, there were no direct effects from poverty or the perceived neighborhood environment on depressive symptoms. Although randomized controlled trials changing neighborhood disadvantage or poverty are almost nonexistent and not particularly feasible, though notable examples do exist (Ludwig et al., 2011), our findings suggest that interventions could focus on changing modifiable factors that mediate relationships between neighborhood disadvantage and health. Furthermore, other neighborhood aspects, such as social cohesion or resources for physical activity, might be changed using relatively easy methods (e.g., increasing vegetation and common spaces to encourage social interaction (Kweon et al., 1998) and improving infrastructure such as lighting and sidewalks to encourage physical activity (Hajna et al., 2016)).

Interestingly, the strongest pathway through which neighborhood characteristics influenced depressive symptoms was loneliness. At least two previous studies have found that neighborhood residential satisfaction, social connections, safety, and collective efficacy are associated with loneliness (Prieto-Flores et al., 2011; Kearns et al., 2015), although not many studies have examined relationships between neighborhoods and loneliness. This lack of research is surprising since social relationships are fundamental among primates (Harlow and Harlow, 1966) and directly influence biological processes underlying health outcomes (Uchino, 2006). Indeed, in a meta-analysis of 148 longitudinal studies, Holt-Lundstad et al. found a 50\% reduction in mortality for individuals with strong social relationships, which was comparable with reductions in mortality attributable to quitting smoking (Holt-Lunstad et al., 2010). As loneliness and social isolation continue to emerge as risk factors for premature mortality (Holt-Lunstad, 2017), our findings suggest that interventions designed to improve depressive symptoms among older adults living in primarily rural neighborhoods may choose to focus on loneliness. This need not be to the exclusion of perceived individual control and physical activity, each of which also emerged as significant, but weaker, mediators.

It should be noted that loneliness and depressive symptoms are related to one another. Indeed, one of the items in the CES-D asks about loneliness. However, studies (using factor analysis and SEM) have shown that these concepts can be thought of as related but conceptually distinct (Cacioppo et al., 2006). For instance, in a longitudinal study of adults aged 50-67 in Illinois, loneliness and depressive symptoms were associated with one another (controlling for demographic and other psychosocial variables), but emerged as separate constructs with reciprocal influence in latent variable growth models (Cacioppo et al., 2006). Evidence from our study confirms these findings given that loneliness was associated with both somatic and non-somatic depressive symptoms factors. Thus, our results suggest that loneliness is associated with depressive symptoms even when depressive symptoms is modeled without the item related to loneliness. Moreover, the fact that the CES-D contains many items (19/20) that are not related to loneliness suggests that there is much to depressive symptoms besides loneliness.

We also found that perceived individual control and physical activity were significant, albeit weaker, mediators of the effects of perceived neighborhood environment on depressive symptoms. A number of studies have found strong relationships between neighborhood characteristics and physical activity (McNeill et al., 2006; Sallis et al., 2009), 
including among older adults (Yen et al., 2009). Research has also shown that greater physical activity can have protective effects against depression (Strawbridge et al., 2002). That we found physical activity to mediate the relationship between perceived neighborhood environment and depressive symptoms is therefore perhaps unsurprising. Less research has established links between neighborhood characteristics and perceived individual control, however some studies have found significant associations (Moore et al., 2010). Researchers hypothesize that neighborhoods with higher socioeconomic status and greater informal social control (i.e., neighborhoods in which residents are able to help regulate and keep their neighborhood safe) can increase opportunities and resources available to residents, thereby making residents feel more in control over their own circumstances (Moore et al., 2010). Perceived individual control is also thought to be a key component of successful coping strategies; for instance, in dealing with stressful life events, individuals with greater perceived control are more able to respond in appropriate, adaptive ways (Skinner and Zimmer-Gembeck, 2011; Dijkstra and Homan, 2016). In future interventions and policies designed to change neighborhood characteristics and/or perceptions of neighborhood characteristics, it may be helpful to measure and assess how the three significant mediators identified here (loneliness, physical activity, and perceived individual control) are associated with outcomes. This monitoring, which could occur during process evaluations, could help researchers understand how interventions are effective or ineffective (Fairchild and McDaniel, 2017). If researchers find significant mediated pathways, then they could allocate more resources to target those mechanisms in future studies. Non-significant pathways can also tell researchers that those mechanisms may not be important and resources can be more effectively allocated.

In our study and as in previous research (Weden et al., 2008), we found stronger associations with depressive symptoms for neighborhood perceptions versus area-level measures of the neighborhood environment that are independent of residents' perception (in this case, neighborhood poverty). It is important to note that perceptions of neighborhood variables are not true measures of the "neighborhood" or "contextual neighborhood effects." Instead, they are individual-level characteristics that are distinct from area-level estimates of the neighborhood. Both types of measures (area-level measures of neighborhood environment and self-reported perceptions of neighborhood environment) are important to examine when conducting research on neighborhoods and health since they provide different pieces of information (Weden et al., 2008). For instance, area-level measures of neighborhood environment are not subject to self-report bias and provide rich information that can be qualitatively hard for residents to provide (e.g., \% of residents in poverty). However, they are also usually based on census data and may not provide information on the full range of neighborhood domains that influence health. Perceptions of neighborhood environment, on the other hand, may more directly align with individual's experiences and reflect how individuals interact with their neighborhoods, but are typically limited by same source bias. In other words, individuals with a particular disposition (i.e., individuals who are less physically active or individuals with more chronic conditions) may rate their environments as less satisfactory than individuals with a different disposition (Weden et al., 2008). Importantly, with SEM, we are able to partly control for these effects by regressing neighborhood perceptions on individual-level characteristics, such as age, race, BMI, and others (Weden et al., 2008). While it is possible that other unmeasured variables may have affected individuals' perceptions of their neighborhood environments, our analyses begin to disentangle the potential bias that self-reported assessments of neighborhoods may contain (Weden et al., 2008) although other biases (e.g., reverse causality) remain possible interpretations of findings.

This is one of few studies that has focused on neighborhood characteristics among older adults living in primarily rural neighborhoods. Our findings suggest that characteristics of rural neighborhoods, like those of urban neighborhoods, are influential for the health and wellbeing of older adults. This finding is perhaps unsurprising given the large body of research documenting the importance of neighborhoods on health. However, we did find that perceived neighborhood characteristics were particularly influential. Rural neighborhoods can be particularly challenging to define and while many researchers examining urban neighborhoods use administrative units, such as census block groups, such an approach may not work for rural neighborhoods since the same administrative unit will span a larger distance in sparsely populated areas (De Marco and De Marco, 2010). For this reason, perceived neighborhood environment may more closely reflect an individual's experience with what they understand to be their neighborhood.

In 2014, $14.5 \%$ (46 million) of the US population was aged 65 or older; by 2060, this figure will reach $23.5 \%$ (98 million) (U.S. Census Bureau, 2014). As adults continue to live longer, health care spending will likely increase, particularly for chronic diseases, which represent 95\% of all health care costs for older adults in the US (Hoffman et al., 1996). Innovative strategies to maintain and promote the quality of life of older adults are needed. One such strategy is promoting "aging in place" including facilitating older adults remaining in their own "homes and communities safely, independently, and comfortably, regardless of age, income, or ability level" (Centers for Disease Control and Prevention, 2017). Despite the importance of both home and community environments, most interventions tailored to older adults have focused on making improvements to individual homes (e.g., making modifications and adaptions to homes in order to prevent accidents or falls, improving functional ability of features in homes, providing services in homes, removing barriers that would prevent older adults from continuing to live at home, etc.) (Wiles et al., 2012). The results from this study suggest that both poverty and perceived neighborhood environment are important correlates of quality of life and that actionable strategies to improve them (e.g., the focus on common spaces, etc. Noted above (Kweon et al., 1998) (Brown et al., 2009)) that should be explored in designing public health interventions for older adults in rural areas.

\subsection{Limitations}

There are several limitations to our findings. First, because we used cross-sectional, observational data, we were unable to assess temporal order. Causal inference methods for mediation have been developed to more accurately quantify direct and indirect effects by using sensitivity analyses to examine potential violations of assumptions (e.g., no measured confounding on different pathways from exposures to outcomes) (VanderWeele, 2016; Petersen et al., 2006). While causal inference methods have a number of benefits over traditional methods for assessing mediation, we chose to use SEM because we estimated multiple sequential mediators, we were interested in analyzing several latent variables, and we needed to control for clustering of observations within neighborhoods. It is important to note that a number of requirements would need to be met before using our findings to make causal claims (e.g., theory was used to decide how variables should be ordered, competing explanations are ruled out, etc.) (Preacher et al., 2011).

Second, since all measures (except neighborhood poverty) were subject to self-report, it is possible that depressed or lonely individuals could have rated their neighborhoods differently than individuals who 
were not depressed or not lonely. Third, we did not control for individual-level income data, which may have partially accounted for the observed effects, especially those related to neighborhood poverty. While we included measures of education and health insurance status as control variables, which have been used as proxies of income in previous studies, further research controlling for income and examining interactions between neighborhood income and individual income will be important.

Fourth, there was a limited amount of missing data for control variables and a small number of observations (approximately $8.2 \%$ of the sample) were excluded from analyses, which could have biased results. Fifth, this study relied on a specific population—older adults in Johnston County, NC. The use of this specific population may limit generalizability to other settings, such as other counties in NC or states in the US and other populations. However, prevalence of chronic disease in this sample $(90.9 \%)$ was similar to prevalence reported from a large, nationally representative sample of older adults in 2008 (92.2\%) (Hung et al., 2011). Sixth, although we examined loneliness, perceived individual control, and physical activity as constructs that were separate from depressive symptoms, it is possible that they could represent symptoms of depression. Seventh, the RMSEA value for loneliness in our CFA was higher than our a prioi criterion of 0.08 , which could have inflated some fit indices.

Finally, it is also important to note that participants included in these analyses were selected from a prospective cohort study and originally invited to participate between 1991 and 1997 (baseline) or 2003-2004 (for cohort enrichment). By the T2 wave of data collection (2006-2011), many individuals had died. It is possible that individuals surviving to the T2 wave of data collection may have been healthier at baseline than those not studied at T2 (referred to as "survivor bias"). Indeed, compared to participants not included in the T2 wave, participants included in the T2 wave were significantly more likely at baseline to be younger, female, or White; to have a high school degree or higher, have a high managerial or professional job, and live in a neighborhood with fewer households below the poverty line; and to have a BMI of 30 or greater, fewer comorbidities, and lower CES-D scores. These additional analyses can be found in the Appendix (Table F).

\section{Conclusions}

In this sample of mostly rural, older adults of whom many had radiographic knee OA $(44.5 \%)$ or other chronic conditions (total $91 \%$ ), poverty and perceived neighborhood environment were associated with reports of depressive symptoms through loneliness, perceived individual control, and physical activity. Specifically, poverty was associated with worse perceived neighborhood environment. In turn, a better perceived neighborhood environment was associated with less loneliness, an increased sense of control, and increased physical activity, which were then associated with fewer depressive symptoms, altogether accounting for $42 \%$ of the variance in depressive symptoms (along with control variables). Loneliness was the strongest mediator of neighborhood characteristics on depression. These findings suggest that both individual-level mediators and neighborhood context are important correlates of depressive symptoms among older adults. Aging in place interventions, in particular, could focus attention on how neighborhood environment could be improved, in addition to making modifications to older adults' individual home environments.

\section{Contributors}

JMJ designed and oversaw the original parent study. LFC designed the ancillary study that added socioeconomic status and neighborhood variables to the parent study. SDK and EBF designed the current study, which relied on data from the parent and ancillary study. SDK wrote the manuscript. JMJ and LFC obtained funding. SDK analyzed the data, with guidance and help from NCG. SDK had full access to the data in the study and takes responsibility for the integrity of the data and the accuracy of the data analysis. SDK acts as guarantor. All authors contributed to reviewing drafts and revisions and approved the final version.

\section{Ethics approval}

At baseline, all participants provided informed written consent at the time of recruitment. The study was approved by the Institutional Review Boards of the University of North Carolina Schools of Medicine and Public Health (IRB \# 92-0583) and the Centers for Disease Control and Prevention.

\section{Transparency declaration}

The lead author (SDK) affirms that the manuscript is an honest, accurate, and transparent account of the study being reported; that no important aspects of the study have been omitted; and that any discrepancies from the study as originally planned have been explained.

\section{Funding and role of funding source}

The parent study was supported in part by the Association of Schools of Public Health and the Centers for Disease Control and Prevention (S043, S1734, S3486), the Centers for Disease Control and Prevention (U01 DP003206 and U01 DP006266), and by the National Institute of Arthritis and Musculoskeletal and Skin Diseases (RO1 AR053898-P60 AR30701, P60 AR049465, P60 AR064166). All statements in this publication, including its findings and conclusions, are solely those of the authors and do not necessarily represent the views of the Associations of Schools of Public Health, CDC or NIAMS. Support for this study was also provided by a Dissertation Completion Fellowship from the University of North Carolina at Chapel Hill Graduate School. This research was independent from funders. The funder had no role in the study design; in the collection, analysis, and interpretation of data; in the writing of the report; or in the decision to submit the article for publication.

\section{Declaration of competing interest}

The authors declare: no financial relationships with any organizations that might have an interest in the submitted work in the previous three years; no other relationships or activities that could appear to have influenced the submitted work.

\section{Appendix B. Supplementary data}




\section{Appendix}

Table A

Measures

\begin{tabular}{|c|c|c|}
\hline $\begin{array}{l}\text { Construct and time point if } \\
\text { applicable }\end{array}$ & Scale Name & Item(s) \\
\hline Depression (T2) & CES-D & $\begin{array}{l}\text { I was bothered by things that usually don't bother me. } \\
\text { I did not feel like eating; my appetite was poor. } \\
\text { I felt that I could not shake off the blues even with help } \\
\text { from my family or friends. } \\
\text { I felt I was just as good as other people. } \\
\text { I had trouble keeping my mind on what I was doing. } \\
\text { I felt depressed. } \\
\text { I felt that everything I did was an effort. } \\
\text { I felt hopeful about the future. } \\
\text { I thought my life had been a failure. } \\
\text { I felt fearful. } \\
\text { My sleep was restless. } \\
\text { I was happy. } \\
\text { I talked less than usual. } \\
\text { I felt lonely. } \\
\text { People were unfriendly. } \\
\text { I enjoyed life. } \\
\text { I had crying spells. } \\
\text { I felt sad. } \\
\text { I felt that people dislike me. } \\
\text { I could not get "going." }\end{array}$ \\
\hline Neighborhood poverty & - & $\begin{array}{l}\text { Block group household poverty compiled from } 2010 \\
\text { census data. }\end{array}$ \\
\hline $\begin{array}{l}\text { Neighborhood social } \\
\text { cohesion }\end{array}$ & $\begin{array}{l}\text { Sampson et al.'s } 5 \text { item } \\
\text { measure of Social } \\
\text { Cohesion and Trust }\end{array}$ & $\begin{array}{l}\text { People around here are willing to help their neighbors. } \\
\text { This is a close-knit or unified neighborhood. } \\
\text { People in my neighborhood can't be trusted. } \\
\text { People in my neighborhood don't get along with each } \\
\text { other. } \\
\text { People in my neighborhood do not share the same } \\
\text { values. }\end{array}$ \\
\hline $\begin{array}{l}\text { Neighborhood access to } \\
\text { physical activity and } \\
\text { walking resources }\end{array}$ & $\begin{array}{l}\text { Walking and Exercise } \\
\text { Environment scale }\end{array}$ & $\begin{array}{l}\text { My neighborhood offers many opportunities to be } \\
\text { physically active. } \\
\text { Local sports clubs and other providers in my } \\
\text { neighborhood offer many opportunities to get exercise. } \\
\text { It is pleasant to walk in my neighborhood. } \\
\text { There are enough trees in my neighborhood to provide } \\
\text { shade. } \\
\text { My neighborhood has heavy traffic } \\
\text { There are busy roads to cross when out for walks in my } \\
\text { neighborhood. } \\
\text { In my neighborhood, it is easy to walk to places. } \\
\text { There are stores within walking distance of my home. } \\
\text { On my neighborhood, the streets and sidewalks are in } \\
\text { good condition. } \\
\text { I often see other people walking in my neighborhood. } \\
\text { I often see other people exercise (for example, jog, } \\
\text { bicycle, play sports) in my neighborhood. }\end{array}$ \\
\hline $\begin{array}{l}\text { Neighborhood perceived } \\
\text { safety }\end{array}$ & - & $\begin{array}{l}\text { I feel safe walking in my neighborhood during the } \\
\text { evening. } \\
\text { My neighborhood is safe from crime. } \\
\text { Violence is a problem in my neighborhood. }\end{array}$ \\
\hline Race/ethnicity & - & White or Black/African American \\
\hline Gender & - & Male/Female \\
\hline Age & - & Age \\
\hline BMI & - & Measured weight (to the nearest pound) \\
\hline \multirow[t]{11}{*}{ Education } & - & $\begin{array}{l}\text { What is the highest grade or year of school that you have } \\
\text { completed, including trade or vocational school or } \\
\text { college? }\end{array}$ \\
\hline & & 00 through 12 Grade school \\
\hline & & 13 GED \\
\hline & & 14 vocational, one year \\
\hline & & 15 vocational, two years \\
\hline & & 16 vocational, three years \\
\hline & & 17 college, one year \\
\hline & & 18 college, two years \\
\hline & & 19 college, three years \\
\hline & & 20 college, four years \\
\hline & & $\begin{array}{l}21 \text { graduate or professional school with advanced } \\
\text { degrees }\end{array}$ \\
\hline
\end{tabular}

Notes

Response options range from 0 (rarely or none of the time) to 3 (most or all of the time), which refer to frequency of the symptoms in the past week. Score totals for individuals with more than four missing responses were not calculated. After reverse coding, items are summed to create a total score that ranged from 0 (best possible) to 60 (worst).

Analyzed as a continuous variable.

All items were assessed on a 5-point likert response scale (1 strongly agree to 5 strongly disagree). After reverse coding any necessary items, responses were summed and ranged from 5 to 25, with higher scores indicating more social cohesion. Responses of "don't know" were combined with responses that indicated "neutral", in line with Sampson et al.'s original analysis of this variable.

All items were assessed on a 5-point likert response scale (1 strongly agree to 5 strongly disagree) and after reverse coding, were summed, where higher scores indicate more access. Responses of "don't know" were combined with responses that indicated "neutral".

All items were assessed on a 5-point likert response scale (1 strongly agree to 5 strongly disagree) and after reverse coding any necessary items, summed, where higher scores indicate more safety. Responses of "don't know" were combined with responses that indicated "neutral".

Calculated BMI

Education was used as a dichotomous variable ( 0 completed less than 12 years of formal schooling, 1 completed 12 years or more). 
Table A

(continued)

\begin{tabular}{|c|c|c|c|}
\hline $\begin{array}{l}\text { Construct and time point if } \\
\text { applicable }\end{array}$ & Scale Name & Item(s) & Notes \\
\hline Health insurance & - & $\begin{array}{l}\text { Do you now have health insurance through ... ? } \\
\text { None } \\
\text { Work or union } \\
\text { Medicare A } \\
\text { Medicare B } \\
\text { Medicare D } \\
\text { Medicaid or public aid } \\
\text { Grange Farm Bureau } \\
\text { Medical Society, or Group Retirement Plan } \\
\text { Direct purchase from insurance company by yourself } \\
\text { Veterans Administration } \\
\text { CHAMPUS-coverage for military personnel and } \\
\text { dependents } \\
\text { Any other plan? }\end{array}$ & $\begin{array}{l}\text { Insurance status was dichotomized as any (coded as } 1 \text { ) or } \\
\text { none (coded as } 0 \text { ). }\end{array}$ \\
\hline $\begin{array}{l}\text { Number of comorbidities } \\
\text { (T2) }\end{array}$ & - & $\begin{array}{l}\text { Please tell me which of the following conditions or } \\
\text { illnesses a DOCTOR, NURSE, or HEALTH PROFESSIONAL } \\
\text { has told you that you have NOW. } \\
\text { Heart disease (heart attack, angina, congestive heart } \\
\text { failure or other heart condition) } \\
\text { High blood pressure (hypertension) } \\
\text { Lung disease (asthma, TB, chronic bronchitis, } \\
\text { emphysema, chronic allergy or other chronic lung } \\
\text { problem) } \\
\text { Vascular disease (stroke or circulation problems) } \\
\text { Ulcer (stomach ulcer or GERD) } \\
\text { Liver disease } \\
\text { Cancer } \\
\text { Anxiety/depression } \\
\text { Anemia } \\
\text { Diabetes } \\
\text { Kidney disease (kidney stone or renal failure) }\end{array}$ & $\begin{array}{l}\text { A comorbidity index of } 11 \text { diseases (heart disease, high blood } \\
\text { pressure, lung disease, cardiovascular disease, ulcer, liver } \\
\text { disease, cancer, anxiety/depression, anemia, diabetes, and } \\
\text { kidney disease) was created and defined as the sum of } \\
\text { positive responses for individual diseases. }\end{array}$ \\
\hline Physical activity & $\begin{array}{l}\text { Behavioral Risk Factor } \\
\text { Surveillance System }\end{array}$ & $\begin{array}{l}\text { Moderate activities are defined as any activity performed } \\
\text { for at least } 10 \text { min at a time, such as brisk walking, } \\
\text { bicycling, vacuuming, gardening, or anything else that } \\
\text { causes some increase in breathing or heart rate. } \\
\text { Vigorous activities are defined as any activity performed } \\
\text { for at least } 10 \text { min at a time, such as running, aerobics, } \\
\text { heavy yard work, or anything else that causes large } \\
\text { increases in breathing or heart rate. } \\
\text { Thinking about the MODERATE activities that you do } \\
\text { IN A USUAL WEEK, do you do MODERATE activities } \\
\text { for at least } 10 \text { min at a time, such as brisk walking, } \\
\text { bicycling, vacuuming, gardening or anything else that } \\
\text { causes small increases in breathing or heart rate? } \\
\text { How many DAYS PER WEEK do you do these } \\
\text { MODERATE activities for at least } 10 \text { min at a time? } \\
\text { On days when you do MODERATE activities for at least }\end{array}$ & $\begin{array}{l}\text { Based on responses to questions, individuals were } \\
\text { classified as Inactive (participants that report doing no } \\
\text { moderate or vigorous physical activity) } \\
\text { Insufficiently active (participants that report doing } \\
\text { insufficient moderate or vigorous physical activity to meet } \\
\text { recommendations, i.e. participants that reported less than } \\
5 \text { days of moderate activity with } 30 \text { or more minutes per } \\
\text { day and less than } 3 \text { days of vigorous activity with } 20 \text { or } \\
\text { more minutes per day) } \\
\text { Active (participants that report that report doing enough } \\
\text { moderate or vigorous physical activity to meeting the } \\
\text { recommendations, i.e., participants that reported } 5 \text { or } \\
\text { more days of moderate activity with } 30 \text { or more minutes } \\
\text { per day and/or } 3 \text { or more days of vigorous activity with } 20 \\
\text { or more minutes per day) }\end{array}$ \\
\hline
\end{tabular}

On days when you do MODERATE activities for at least $10 \mathrm{~min}$ at a time, how much TOTAL TIME PER DAY do you spend doing these activities? (measured in hours) On days when you do MODERATE activities for at least $10 \mathrm{~min}$ at a time, how much TOTAL TIME PER DAY do you spend doing these activities? (measured in minutes)

Now thinking about VIGOROUS physical activities you do IN A USUAL WEEK, do you do VIGOROUS activities for at least $10 \mathrm{~min}$ at a time, such as running, aerobics, heavy yard work, or anything else that causes large increases in breathing or heart rate?

How many DAYS PER WEEK do you do these VIGOROUS activities for at least $10 \mathrm{~min}$ at a time? On days when you do VIGOROUS activities for at least $10 \mathrm{~min}$ at a time, how much TOTAL TIME PER DAY do you spend doing these activities? (measured in hours) On days when you do VIGOROUS activities for at least 10 min at a time, how much TOTAL TIME PER DAY do you spend doing these activities? (measured in minutes)

How often are you bothered by not having a close companion?
Radiographic knee OA was assessed using clinical exams. Posterior-anterior radiographs of the knee were obtained and interpreted by a musculoskeletal radiologist using the Kellgren-Lawrence (KL) scale from 0 to 4 . Presence of radiographic OA was defined as KL grade at 2 or higher. All items were assessed on a 5-point likert response scale (1 strongly agree to 5 strongly disagree), reverse coded, and summed, where higher scores indicate more loneliness. 
(continued)

\begin{tabular}{|c|c|c|c|}
\hline $\begin{array}{l}\text { Construct and time point if } \\
\text { applicable }\end{array}$ & Scale Name & Item(s) & Notes \\
\hline $\begin{array}{l}\text { Perceived individual } \\
\text { control } \\
\text { Chronic conditions (for } \\
\text { sensitivity analysis) }\end{array}$ & $\begin{array}{l}\text { Perceived Control Scale } \\
\text { Disease Inventory Index } \\
\text { and radiography/KL } \\
\text { scores }\end{array}$ & $\begin{array}{l}\text { How often are you bothered by not seeing people you } \\
\text { feel close to? } \\
\text { How often are you bothered by not having enough } \\
\text { close friends? } \\
\text { How often are you bothered by not having someone } \\
\text { who shows you love and affection? } \\
\text { I have control over the decisions that affect my life. } \\
\text { I am satisfied with the amount of control I have over } \\
\text { decisions that affect my life. } \\
\text { Knee or hip OA } \\
\text { Heart disease (heart attack, angina, congestive heart } \\
\text { failure or other heart condition) } \\
\text { Hypertension } \\
\text { Lung disease (including asthma, tuberculosis, chronic } \\
\text { bronchitis, emphysema, chronic allergy or another } \\
\text { chronic lung problem) } \\
\text { Vascular disease (including: stroke or circulation } \\
\text { problems) } \\
\text { Liver disease } \\
\text { Cancer } \\
\text { Diabetes } \\
\text { Kidney disease/renal failure }\end{array}$ & $\begin{array}{l}\text { Both items were assessed on a 5-point likert response scale } \\
\text { ( } 1 \text { strongly agree to } 5 \text { strongly disagree), reverse coded, } \\
\text { and summed, where higher scores indicate more control. } \\
\text { All conditions were measured using the Disease Inventory } \\
\text { Index, except for knee and hip OA for which we used } \\
\text { radiography and KL scores. }\end{array}$ \\
\hline
\end{tabular}

Table B

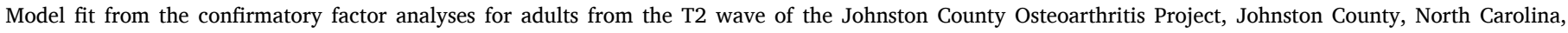
2006-2011, n 1697

\begin{tabular}{|c|c|c|c|c|c|c|c|}
\hline Variable & Items & Modifications & $\begin{array}{l}\text { Chi-Square } \\
\text { (p-value) }^{\text {a,b }}\end{array}$ & $\begin{array}{l}\text { CFI } \\
\mathrm{a}, \mathrm{c}\end{array}$ & $\begin{array}{l}\text { TLI } \\
\mathrm{a}, \mathrm{c}\end{array}$ & RMSEA $^{\text {a,d }}$ & $\begin{array}{l}\text { Cronbach's } \\
\text { Alpha }\end{array}$ \\
\hline Depressive symptoms & All 20 items & - & $\begin{array}{l}810.71(\mathrm{p}< \\
0.0001)\end{array}$ & 0.96 & 0.95 & $\begin{array}{l}0.05 \\
(0.05 \\
0.05)\end{array}$ & 0.88 \\
\hline \multirow[t]{2}{*}{$\begin{array}{l}\text { Perceived neighborhood } \\
\text { social cohesion }\end{array}$} & All 5 items & - & $\begin{array}{l}386.66(\mathrm{p}< \\
0.0001)\end{array}$ & 0.95 & 0.89 & $\begin{array}{l}0.21 \\
(0.20 \\
0.23)\end{array}$ & 0.86 \\
\hline & All 5 items & $\begin{array}{l}\text { Correlated two items, which } \\
\text { were reverse coded. }\end{array}$ & $\begin{array}{l}27.61(\mathrm{p}< \\
0.0001)\end{array}$ & 0.99 & 0.99 & $\begin{array}{l}0.06 \\
(0.04 \\
0.08)\end{array}$ & 0.86 \\
\hline \multirow[t]{2}{*}{$\begin{array}{l}\text { Perceived neighborhood } \\
\text { resources for physical } \\
\text { activity and walking }\end{array}$} & All 11 items & - & $\begin{array}{l}6995.897(\mathrm{p} \\
<0.0001)\end{array}$ & 0.66 & 0.57 & $\begin{array}{l}0.31 \\
(0.30 \\
0.31)\end{array}$ & 0.73 \\
\hline & $\begin{array}{l}4 \text { items (Shaw and McKay, 1996; Brown et al., } \\
\text { 2004; Carpiano, 2006; Manini, 2013) }\end{array}$ & $\begin{array}{l}\text { Only included } 4 / 11 \text { items } \\
\text { since the initial model had } \\
\text { poor fit. }{ }^{f}\end{array}$ & $\begin{array}{l}7.71(\mathrm{p} \\
0.02)\end{array}$ & 0.99 & 0.99 & $\begin{array}{l}0.04 \\
(0.01 \\
0.07)\end{array}$ & 0.65 \\
\hline $\begin{array}{l}\text { Perceived neighborhood } \\
\text { safety }\end{array}$ & 3 items & - & - & - & - & - & 0.70 \\
\hline Loneliness & All 4 items & - & $\begin{array}{l}51.70(\mathrm{p}< \\
0.0001)\end{array}$ & 0.99 & 0.96 & $\begin{array}{l}0.12 \\
(0.10 \\
0.15)\end{array}$ & 0.75 \\
\hline Perceived individual control ${ }^{\mathrm{e}}$ & 2 items & - & - & - & - & - & 0.72 \\
\hline $\begin{array}{l}\text { Perceived neighborhood } \\
\text { environment }{ }^{\mathrm{e}}\end{array}$ & $\begin{array}{l}\text { Higher order factor comprised of } \\
\text { neighborhood social cohesion, access to } \\
\text { physical activity and walking resources, and } \\
\text { safety }\end{array}$ & - & - & - & - & - & 0.72 \\
\hline
\end{tabular}

\section{Notes.}

${ }^{a}$ All CFAs controlled for clustering using type complex.

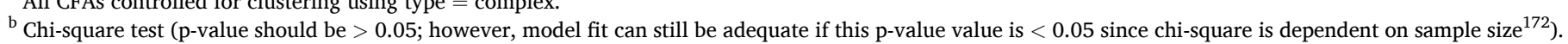

${ }^{c}$ The Comparative Fit Index (CFI) and Tucker-Lewis Index (TLI) (CFI, TLI should be $>0.95^{173,174}$ ).

$\mathrm{d}$ The root mean square error of approximation (RSMEA, should be $<0.06^{175,176}$ ).

e The model fit of factors with 3 or less items cannot be determined since the model would be just identified or not identified.

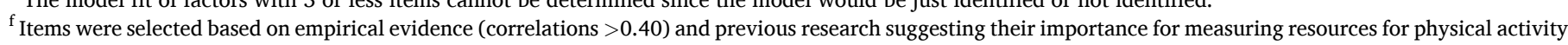
and walking in rural neighborhoods. 
Table C

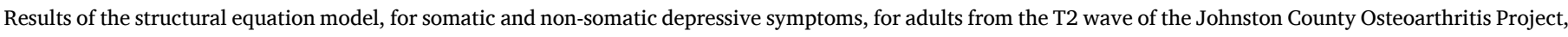
Johnston County, North Carolina, 2006-2011, n 1558.

\begin{tabular}{|c|c|c|c|c|c|c|c|c|c|c|c|}
\hline \multirow{3}{*}{$\begin{array}{l}\text { Exogenous variables } \\
\text { Poverty }\end{array}$} & \multicolumn{11}{|c|}{ Endogenous variables } \\
\hline & \multicolumn{2}{|c|}{$\begin{array}{l}\text { Perceived neighborhood } \\
\text { environment }\end{array}$} & \multicolumn{2}{|c|}{$\begin{array}{l}\text { Physical } \\
\text { activity }\end{array}$} & \multirow{2}{*}{$\begin{array}{l}\text { Loneliness } \\
-\end{array}$} & \multicolumn{2}{|c|}{$\begin{array}{l}\text { Perceived individual } \\
\text { control }\end{array}$} & \multicolumn{2}{|c|}{$\begin{array}{l}\text { Depressive symptoms } \\
\text { (somatic) }\end{array}$} & \multicolumn{2}{|c|}{$\begin{array}{l}\text { Depressive symptoms } \\
\text { (non-somatic) }\end{array}$} \\
\hline & B & $0.16^{* * *}$ & B & $0.06^{*}$ & & - & & B & 0.07 & B & 0.003 \\
\hline $\begin{array}{l}\text { Perceived neighborhood } \\
\text { environment }\end{array}$ & - & & B & $0.09 * *$ & B $0.41^{* * *}$ & B & $0.61^{* * *}$ & B & 0.02 & B & 0.01 \\
\hline Physical activity & - & & - & & - & - & & B & $0.12^{* * *}$ & B & $0.13^{* * *}$ \\
\hline Loneliness & - & & - & & - & - & & B & $0.37 * * *$ & B & $0.49 * * *$ \\
\hline Perceived individual control & & & & & & - & & B & 0.08 & B & $0.14^{*}$ \\
\hline
\end{tabular}

Notes.

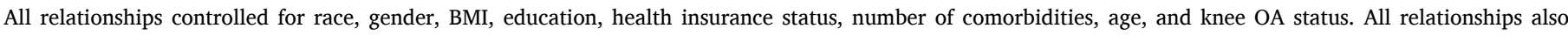
controlled for clustering using type complex. The correlation between somatic and non-somatic symptoms was 0.83 . Beta coefficients are standardized.

$* \mathrm{p}<0.05, * * \mathrm{p}<0.01, * * * \mathrm{p}<0.001$.

Model Fit.

Chi-Square value (p-value): 1659.92, p < 0.001); RMSEA: 0.02 (95\% CI: 0.02, 0.02); CFI: 0.96; TLI: 0.96 .

Indirect Effects.

Perceived neighborhood environment ê Physical activity ê Depressive symptoms (somatic): B $\quad 0.01, \mathrm{p} \quad 0.003$.

Perceived neighborhood environment ê Physical activity ê Depressive symptoms (non-somatic): B $\quad 0.01, \mathrm{p} \quad 0.006$.

Perceived neighborhood environment ê Loneliness ê Depressive symptoms (somatic): B $\quad 0.15, \mathrm{p}<0.001$.

Perceived neighborhood environment ê Loneliness ê Depressive symptoms (non-somatic): B $\quad 0.20, \mathrm{p}<0.001$.

Perceived neighborhood environment ê Perceived individual control ê Depressive symptoms (somatic) B $0.05, \mathrm{p} \quad 0.06$.

Perceived neighborhood environment ê Perceived individual control ê Depressive symptoms (non-somatic) B 0.08 , $\mathrm{p} \quad 0.02$.

Poverty $\rightarrow$ Physical activity $\rightarrow$ Depressive symptoms (somatic): B $\quad 0.007, p \quad 0.07$.

Poverty $\rightarrow$ Physical activity $\rightarrow$ Depressive symptoms (non-somatic): B $\quad 0.008, \mathrm{p} \quad 0.06$.

Poverty $\rightarrow$ Perceived neighborhood environment $\rightarrow$ Depressive symptoms (somatic): B $\quad 0.003, p \quad 0.65$.

Poverty $\rightarrow$ Perceived neighborhood environment $\rightarrow$ Depressive symptoms (non-somatic): B $\quad 0.001, \mathrm{p} \quad 0.92$.

Poverty ê Perceived neighborhood environment ê Physical activity ê Depressive symptoms (somatic): B 0.002 , p $\quad 0.01$.

Poverty ê Perceived neighborhood environment ê Physical activity ê Depressive symptoms (non-somatic): B $\quad 0.002$, p $\quad 0.01$.

Poverty $\rightarrow$ Perceived neighborhood environment $\rightarrow$ Loneliness $\rightarrow$ Depressive symptoms (somatic): B $\quad 0.02, \mathrm{p}<0.001$.

Poverty $\rightarrow$ Perceived neighborhood environment $\rightarrow$ Loneliness $\rightarrow$ Depressive symptoms (non-somatic): B $0.03, p<0.001$.

Poverty $\rightarrow$ Perceived neighborhood environment $\rightarrow$ Perceived individual control $\rightarrow$ Depressive symptoms (somatic): B $\quad 0.008, \mathrm{p} \quad 0.07$.

Poverty $\rightarrow$ Perceived neighborhood environment $\rightarrow$ Perceived individual control $\rightarrow$ Depressive symptoms (non-somatic): B $0.01, \mathrm{p} \quad 0.04$

Poverty ê Perceived neighborhood environment ê Physical activity: B $\quad 0.02$, p $\quad 0.009$.

Table D

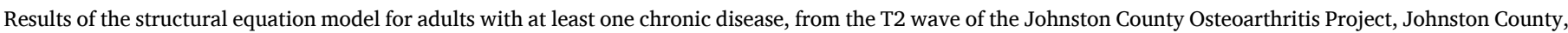
North Carolina, 2006-2011, n 1482.

\begin{tabular}{|c|c|c|c|c|c|c|c|c|c|c|}
\hline \multirow{3}{*}{$\begin{array}{l}\text { Exogenous variables } \\
\text { Poverty }\end{array}$} & \multicolumn{10}{|c|}{ Endogenous variables } \\
\hline & \multicolumn{2}{|c|}{ Perceived neighborhood environment } & \multicolumn{2}{|c|}{ Physical activity } & \multicolumn{2}{|c|}{ Loneliness } & \multicolumn{2}{|c|}{ Perceived individual control } & \multicolumn{2}{|c|}{ Depressive symptoms } \\
\hline & $\mathrm{B}$ & $0.17^{* * *}$ & B & 0.05 & - & & - & & B & 0.03 \\
\hline Perceived neighborhood environment & - & & B & $0.11^{* *}$ & B & $0.40 * * *$ & B & $0.60 * * *$ & $\mathrm{~B}$ & 0.01 \\
\hline Physical activity & - & & - & & - & & - & & $\mathrm{B}$ & $0.16^{* * *}$ \\
\hline Loneliness & - & & - & & - & & - & & B & $0.49^{* * *}$ \\
\hline Perceived individual control & & & & & & & - & & $\mathrm{B}$ & $0.14^{* *}$ \\
\hline
\end{tabular}

Notes.

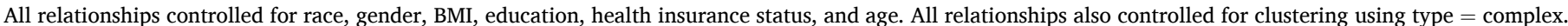
Beta coefficients are standardized.

*p $<0.05, * * \mathrm{p}<0.01, * * * \mathrm{p}<0.001$

Model Fit.

Chi-Square value (p-value): 1672.79, p < 0.001); RMSEA: 0.02 (95\% CI: 0.02, 0.02); CFI: 0.96; TLI: 0.96 .

Indirect Effects.

Perceived neighborhood environment ê Physical activity ê Depressive symptoms: B $\quad 0.02, \mathrm{p} \quad 0.003$.

Perceived neighborhood environment ê Loneliness ê Depressive symptoms: B $\quad 0.19, \mathrm{p}<0.001$.

Perceived neighborhood environment ê Perceived individual control ê Depressive symptoms: B $\quad 0.08, \mathrm{p} \quad 0.003$.

Poverty $\rightarrow$ Physical activity $\rightarrow$ Depressive symptoms: B $\quad 0.008, \mathrm{p} \quad 0.17$.

Poverty $\rightarrow$ Perceived neighborhood environment $\rightarrow$ Depressive symptoms: B $\quad 0.001, p \quad 0.87$.

Poverty ê Perceived neighborhood environment ê Physical activity ê Depressive symptoms: B $\quad 0.003, p \quad 0.006$.

Poverty $\rightarrow$ Perceived neighborhood environment $\rightarrow$ Loneliness $\rightarrow$ Depressive symptoms: B $\quad 0.03, p<0.001$.

Poverty $\rightarrow$ Perceived neighborhood environment $\rightarrow$ Perceived individual control $\rightarrow$ Depressive symptoms: B $0.01, \mathrm{p} \quad 0.02$

Poverty ê Perceived neighborhood environment ê Physical activity: B $\quad 0.02, \mathrm{p} \quad 0.004$. 
Table E

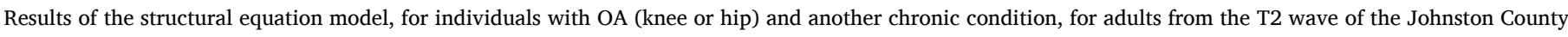
Osteoarthritis Project, Johnston County, North Carolina, 2006-2011, n 864

\begin{tabular}{|c|c|c|c|c|c|c|c|c|c|c|}
\hline \multirow{3}{*}{$\begin{array}{l}\text { Exogenous variables } \\
\text { Poverty }\end{array}$} & \multicolumn{10}{|c|}{ Endogenous variables } \\
\hline & \multicolumn{2}{|c|}{ Perceived neighborhood environment } & \multicolumn{2}{|c|}{ Physical activity } & \multicolumn{2}{|c|}{ Loneliness } & \multicolumn{2}{|c|}{ Perceived individual control } & \multicolumn{2}{|c|}{ Depressive symptoms } \\
\hline & B & $0.20 * * *$ & B & $0.09 *$ & - & & - & & B & 0.02 \\
\hline Perceived neighborhood environment & - & & B & 0.05 & B & $0.44 * * *$ & B & $0.56^{* * *}$ & $\mathrm{~B}$ & 0.05 \\
\hline Physical activity & - & & - & & - & & - & & B & $0.21^{* * *}$ \\
\hline Loneliness & - & & - & & - & & - & & B & $0.52^{* * *}$ \\
\hline Perceived individual control & & & & & & & - & & B & 0.07 \\
\hline
\end{tabular}

Notes.

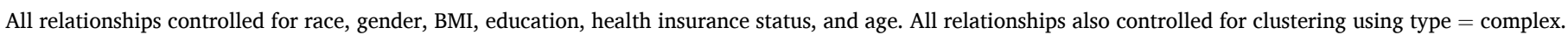
Beta coefficients are standardized.

*p $<0.05, * * \mathrm{p}<0.01, * * * \mathrm{p}<0.001$.

Model Fit.

Chi-Square value (p-value): 1468.69, p < 0.001); RMSEA: 0.03 (95\% CI: 0.02, 0.03); CFI: 0.95; TLI: 0.95.

Indirect Effects.

Perceived neighborhood environment ê Physical activity ê Depressive symptoms: B $\quad 0.01, \mathrm{p} \quad 0.20$.

Perceived neighborhood environment ê Loneliness ê Depressive symptoms: B $\quad 0.22, \mathrm{p}<0.001$.

Perceived neighborhood environment ê Perceived individual control ê Depressive symptoms: B $\quad 0.04, \mathrm{p} \quad 0.14$.

Poverty $\rightarrow$ Physical activity $\rightarrow$ Depressive symptoms: B $\quad 0.02, \mathrm{p} \quad 0.02$.

Poverty $\rightarrow$ Perceived neighborhood environment $\rightarrow$ Depressive symptoms: B $\quad 0.01, p \quad 0.32$.

Poverty ê Perceived neighborhood environment ê Physical activity ê Depressive symptoms: B $\quad 0.002, \mathrm{p} \quad 0.19$.

Poverty $\rightarrow$ Perceived neighborhood environment $\rightarrow$ Loneliness $\rightarrow$ Depressive symptoms: B $\quad 0.05, \mathrm{p}<0.001$

Poverty $\rightarrow$ Perceived neighborhood environment $\rightarrow$ Perceived individual control $\rightarrow$ Depressive symptoms: B $\quad 0.008, \mathrm{p} \quad 0.18$.

Poverty ê Perceived neighborhood environment ê Physical activity: B $\quad 0.01, \mathrm{p} \quad 0.19$.

Table F

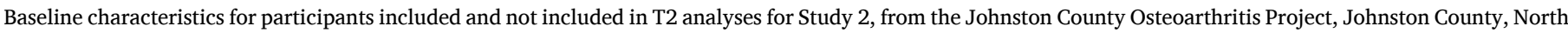
Carolina, 2006-2011

\begin{tabular}{|c|c|c|c|c|c|c|}
\hline & $\begin{array}{l}\text { Baseline characteristics for } \\
\text { participants not included in T2 } \\
\text { analyses } \mathrm{N}(\%) \text { or } \mathrm{N} \text { (mean) }\end{array}$ & $\begin{array}{l}\text { Baseline characteristics for } \\
\text { participants included in T2 } \\
\text { analyses } \mathrm{N}(\%) \text { or } \mathrm{N} \text { (mean) }\end{array}$ & $\begin{array}{l}\mathrm{P} \text { - } \\
\text { value }\end{array}$ & $\begin{array}{l}\text { Baseline characteristics for } \\
\text { participants not included in } \mathrm{T} 2 \\
\text { wave } \mathrm{N}(\%) \text { or } \mathrm{N} \text { (mean) }\end{array}$ & $\begin{array}{l}\text { Baseline characteristics for } \\
\text { participants included in } \mathrm{T} 2 \\
\text { wave } \mathrm{N}(\%) \text { or } \mathrm{N} \text { (mean) }\end{array}$ & P-value \\
\hline \multicolumn{7}{|l|}{ Characteristic } \\
\hline Age, years, mean & $106(60.5)$ & $1558(58.0)$ & $\begin{array}{l}\mathrm{p} \\
0.006\end{array}$ & $2673(62.7)$ & $1664(58.2)$ & $\begin{array}{l}\mathrm{p}< \\
0.0001\end{array}$ \\
\hline \multicolumn{7}{|l|}{ Gender } \\
\hline Male & $28(26.4)$ & $516(33.1)$ & $\begin{array}{l}\mathrm{p} \\
0.15\end{array}$ & $1044(39.1)$ & $544(32.7)$ & $\begin{array}{l}\mathrm{p}< \\
0.0001\end{array}$ \\
\hline Female & $78(73.6)$ & $1042(66.9)$ & & $1629(60.9)$ & $1120(67.3)$ & \\
\hline \multicolumn{7}{|l|}{ Race } \\
\hline White & $68(64.2)$ & $1082(69.5)$ & $\begin{array}{l}\mathrm{p} \\
0.25\end{array}$ & $1671(62.5)$ & $1150(69.1)$ & $\begin{array}{l}\mathrm{p}< \\
0.0001\end{array}$ \\
\hline $\begin{array}{l}\text { Black or African } \\
\text { American }\end{array}$ & $38(35.9)$ & $476(30.6)$ & & $1002(37.5)$ & 514 (30.9) & \\
\hline \multicolumn{7}{|l|}{ Education } \\
\hline High school & $69(68.3)$ & $1225(78.8)$ & $\begin{array}{l}\mathrm{p} \\
0.01\end{array}$ & $1479(55.6)$ & $1294(78.1)$ & $\begin{array}{l}\mathrm{p}< \\
0.0001\end{array}$ \\
\hline$<$ High school & $32(31.7)$ & $330(21.2)$ & & $1183(44.4)$ & 362 (21.9) & \\
\hline \multicolumn{7}{|l|}{ Health insurance } \\
\hline No & $4(3.9)$ & $77(5.1)$ & $\begin{array}{l}\mathrm{p} \\
0.59\end{array}$ & $146(5.9)$ & $81(5.0)$ & $\begin{array}{l}\mathrm{p} \\
0.22\end{array}$ \\
\hline Yes & $99(96.1)$ & $1441(94.9)$ & & $2332(94.1)$ & $1540(95.0)$ & \\
\hline \multicolumn{7}{|l|}{ BMI } \\
\hline$<30$ & $43(41.4)$ & 913 (59.4) & $\begin{array}{l}\mathrm{p} \\
0.003\end{array}$ & $1571(61.7)$ & $956(58.2)$ & $\begin{array}{l}\mathrm{p} \\
0.03\end{array}$ \\
\hline 30 & $61(58.7)$ & $625(40.6)$ & & $976(38.3)$ & $686(41.8)$ & \\
\hline $\begin{array}{l}\text { Number of } \\
\text { comorbidities }\end{array}$ & $106(1.1)$ & $1558(1.0)$ & $\begin{array}{l}\mathrm{p} \\
0.38\end{array}$ & $2670(1.3)$ & $1664(1.0)$ & $\begin{array}{l}\mathrm{p}< \\
0.0001\end{array}$ \\
\hline \multicolumn{7}{|l|}{ Occupation } \\
\hline High SES job & $40(42.6)$ & $774(53.1)$ & $\begin{array}{l}\mathrm{p} \\
0.05\end{array}$ & $910(38.2)$ & $814(52.4)$ & $\begin{array}{l}\mathrm{p}< \\
0.0001\end{array}$ \\
\hline Low SES job & $54(57.5)$ & $685(47.0)$ & & $1472(61.8)$ & 739 (47.6) & \\
\hline $\begin{array}{l}\text { CES-D scores } \\
\text { (range 0-60), } \\
\text { mean }\end{array}$ & $105(7.2)$ & $1545(6.3)$ & $\begin{array}{l}\mathrm{p} \\
0.24\end{array}$ & $2620(7.6)$ & $1650(6.3)$ & $\begin{array}{l}\mathrm{p}< \\
0.0001\end{array}$ \\
\hline $\begin{array}{l}\text { Neighborhood } \\
\text { poverty }\end{array}$ & 100 (18.9) & $1506(18.4)$ & $\begin{array}{l}\mathrm{p} \\
0.63\end{array}$ & $2556(20.4)$ & $1606(18.5)$ & $\begin{array}{l}\mathrm{p}< \\
0.0001\end{array}$ \\
\hline
\end{tabular}




\section{References}

Anderson, J.C., Gerbing, D.W., 1988. Structural equation modeling in practice: a review and recommended two-step approach. Psychol. Bull. 103, 411.

Bentler, P.M., 1990. Comparative fit indexes in structural models. Psychol. Bull. 107, 238-246.

Berkman, L.F., Glass, T., 2000. Social integration, social networks, social support, and health. Soc. Epidemiol. 1, 137-173.

Blair, A., Ross, N.A., Gariepy, G., Schmitz, N., 2014. How do neighborhoods affect depression outcomes? A realist review and a call for the examination of causal pathways. Soc. Psychiatry Psychiatr. Epidemiol. 49, 873-887.

Bowen, N.K., Guo, S., 2011. Structural Equation Modeling. Oxford University Press. Braveman, P., Egerter, S., Williams, D.R., 2011. The social determinants of health: coming of age. Annu. Rev. Public Health 32, 381-398.

Brown, G.K., Wallston, K.A., Nicassio, P.M., 1989. Social support and depression in rheumatoid arthritis: a one-year prospective study. J. Appl. Soc. Psychol. 19 1164-1181.

Brown, A.F., Ettner, S.L., Piette, J., et al., 2004. Socioeconomic position and health among persons with diabetes mellitus: a conceptual framework and review of the literature. Epidemiol. Rev. 26, 63-77.

Brown, A.F., Ang, A., Pebley, A.R., 2007. The relationship between neighborhood characteristics and self-rated health for adults with chronic conditions. Am. J. Public Health 97, 926-932.

Brown, S.C., Mason, C.A., Lombard, J.L., et al., 2009. The relationship of built environment to perceived social support and psychological distress in Hispanic elders: the role of "eyes on the street". J Gerontol B Psychol Sci Soc Sci 64, 234-246.

Browning, C.R., Cagney, K.A., 2002. Neighborhood structural disadvantage, collective efficacy, and self-rated physical health in an urban setting. J. Health Soc. Behav. 383-399.

Cabrera-Nguyen, P., 2010. Author guidelines for reporting scale development and validation results in the Journal of the Society for Social Work and Research. J. Soc. Soc. Work. Res. 1, 99-103.

Cacioppo, J.T., Hughes, M.E., Waite, L.J., Hawkley, L.C., Thisted, R.A., 2006. Lonelines as a specific risk factor for depressive symptoms: cross-sectional and longitudinal analyses. Psychol. Aging 21, 140.

Carleton, R.N., Thibodeau, M.A., Teale, M.J., et al., 2013. The center for epidemiologic studies depression scale: a review with a theoretical and empirical examination of item content and factor structure. PLoS One 8, e58067.

Carpiano, R.M., 2006. Toward a neighborhood resource-based theory of social capital for health: can Bourdieu and sociology help? Soc. Sci. Med. 62, 165-175.

Centers for Disease Control and Prevention, 2016. A Data Users Guide to the BRFSS Physical Activity Questions. Retrieved May 21, 2016, from. http://www.cdc.gov/br fss/pdf/PA\%20RotatingCore_BRFSSGuide_508Comp_07252013FINAL.pdf.

Centers for Disease Control and Prevention, 2017. Healthy Places Terminology. Retrieved December 18, 2017, from https://www.cdc.gov/healthyplaces/termin ology.htm. .

Chapman, D.P., Perry, G.S., 2008. Depression as a major component of public health for older adults. Prev. Chronic Dis. 5, A22.

Charles, S., Carstensen, L.L., 2010. Social and emotional aging. Annu. Rev. Psychol. 61, 383-409.

Coty, M.-B., Wallston, K.A., 2010. Problematic social support, family functioning, and subjective well-being in women with rheumatoid arthritis. Women Health 50, $53-70$.

De Marco, A., De Marco, M., 2010. Conceptualization and measurement of the neighborhood in rural settings: a systematic review of the literature. J. Community Psychol. 38, 99-114.

De Vellis, R., De Vellis, B.M., Sauter, S., Harring, K., Cohen, J., 1986. Predictors of pain and functioning in arthritis. Health Educ. Res. 1, 61-67.

Dean, A., Lin, N., 1977. The stress-buffering role of social support. Problems and prospects for systematic investigation. J. Nerv. Ment. Dis. 165, 403-417.

Diez Roux, A.V., Mair, C., Neighborhoods, health, 2010. Ann. N. Y. Acad. Sci. 1186, 125-145.

Dijkstra, M., Homan, A.C., 2016. Engaging in rather than disengaging from stress: effective coping and perceived control. Front. Psychol. 7, 1415.

Echeverria, S.E., Diez-Roux, A.V., Link, B.G., 2004. Reliability of self-reported neighborhood characteristics. J. Urban Health 81, 682-701.

Edwards, M.C., Cheavens, J.S., Heiy, J.E., Cukrowicz, K.C., 2010. A reexamination of the factor structure of the center for epidemiologic studies depression scale: is a onefactor model plausible? Psychol. Assess. 22, 711-715.

Eronen, J., von Bonsdorff, M., Rantakokko, M., Rantanen, T., 2014. Environmental facilitators for outdoor walking and development of walking difficulty in community-dwelling older adults. Eur. J. Ageing 11, 67-75.

Evans, G.W., 2003. The built environment and mental health. J. Urban Health 80, $536-555$.

Fairchild, A.J., McDaniel, H.L., 2017. Best (but oft-forgotten) practices: mediation analysis. Am. J. Clin. Nutr. 105, 1259-1271.

Friedrich, M.J., 2017. Depression is the leading cause of disability around the world. J. Am. Med. Assoc. 317, 1517-1517.

Glass, T.A., Balfour, J.L., 2003. Neighborhoods, aging, and functional limitations. In: Kawachi, I., Berkman, L. (Eds.), Neighborhoods and Health. Oxford University Press, Oxford, UK, pp. 303-334.

Gong, Y., Palmer, S., Gallacher, J., Marsden, T., Fone, D., 2016. A systematic review of the relationship between objective measurements of the urban environment and psychological distress. Environ. Int. 96, 48-57.
Greenberg, P.E., Fournier, A.-A., Sisitsky, T., Pike, C.T., Kessler, R.C., 2015. The economic burden of adults with major depressive disorder in the United States (2005 and 2010). J. Clin. Psychiatry 76, 155-162.

Gunzler, D., Chen, T., Wu, P., Zhang, H., 2013. Introduction to mediation analysis with structural equation modeling. Shanghai Arch. Psychiatr. 25, 390.

Hajna, S., Ross, N.A., Joseph, L., Harper, S., Dasgupta, K., 2016. Neighbourhood walkability and daily steps in adults with type 2 diabetes. PLoS One 11, e0151544. Harlow, H.F., Harlow, M., 1966. Learning to love. Am. Sci. 54, 244-272.

Hoffman, C., Rice, D., Sung, H.Y., 1996. Persons with chronic conditions. Their prevalence and costs. J. Am. Med. Assoc. 276, 1473-1479.

Holt-Lunstad, J., 2017. The potential public health relevance of social isolation and loneliness: prevalence, epidemiology, and risk factors. Public Policy Adm. Res. 27, 127-130.

Holt-Lunstad, J., Smith, T.B., Layton, J.B., 2010. Social relationships and mortality risk: a meta-analytic review. PLoS Med. 7, e1000316.

Hung, W.W., Ross, J.S., Boockvar, K.S., Siu, A.L., 2011. Recent trends in chronic disease, impairment and disability among older adults in the United States. BMC Geriatr. 11, 47.

Israel, B.A., Checkoway, B., Schulz, A., Zimmerman, M., 1994. Health education and community empowerment: conceptualizing and measuring perceptions of individual, organizational, and community control. Health Educ. Q. 21, 149-170.

Jordan, J.M., 2015. An ongoing assessment of osteoarthritis in african Americans and caucasians in North Carolina: the Johnston county osteoarthritis Project. Trans. Am. Clin. Climatol. Assoc. 126, 77-86.

Joreskog, K.G., 1969. A general approach to confirmatory maximum likelihood factor analysis. Psychometrika 34, 183-202.

Kawachi, I., Berkman, L.F., 2014. Social cohesion, social capital, and health. In: Berkman, L.F., Kawachi, I., Glymour, M. (Eds.), Social Epidemiology. Oxford University Press.

Kearns, A., Whitley, E., Tannahill, C., Ellaway, A., 2015. 'Lonesome town'? Is loneliness associated with the residential environment, including housing and neighborhood factors? J. Community Psychol. 43, 849-867.

Kegler, M.C., Alcantara, I., Haardorfer, R., et al., 2015. Rural neighborhood walkability: implications for assessment. J. Phys. Act. Health 12 (Suppl. 1), S40-S45.

Keskinen, K.E., Rantakokko, M., Suomi, K., Rantanen, T., Portegijs, E., 2018. Nature as a facilitator for physical activity: defining relationships between the objective and perceived environment and physical activity among community-dwelling older people. Health Place 49, 111-119.

Kim, D., 2008. Blues from the neighborhood? Neighborhood characteristics and depression. Epidemiol. Rev. 30, 101-117.

Kim, J.-R., Jeong, B., Park, K.-S., Kang, Y.-S., 2016. Association of social capital at the individual level with physical activity in communities with high mortality in Korea. Health Promot. Int. daw017.

Kline, R.B., 2011. Principles and Practice of Structural Equation Modeling. Guilford press.

Kweon, B.-S., Sullivan, W.C., Wiley, A.R., 1998. Green common spaces and the social integration of inner-city older adults. Environ. Behav. 30, 832-858.

Latham, K., Clarke, P.J., 2018. Neighborhood disorder, perceived social cohesion, and social participation among older Americans: findings from the national health \& aging trends study. J. Aging Health 30, 3-26.

Lawton, M.P., Nahemow, L., 1973. Ecology and the Aging Process.

Ludwig, J., Sanbonmatsu, L., Gennetian, L., et al., 2011. Neighborhoods, obesity, and diabetes-a randomized social experiment. N. Engl. J. Med. 365, 1509-1519.

Mair, C., Diez Roux, A.V., Galea, S., 2008. Are neighbourhood characteristics associated with depressive symptoms? A review of evidence. J. Epidemiol. Community Health 62, 940-946, 948 pp. following 946.

Mair, C., Diez Roux, A.V., Shen, M., et al., 2009. Cross-sectional and longitudinal associations of neighborhood cohesion and stressors with depressive symptoms in the multiethnic study of atherosclerosis. Ann. Epidemiol. 19, 49-57.

Manini, T.M., 2013. Mobility decline in old age: a time to intervene. Exerc. Sport Sci. Rev, 41, 2

Martin, K.R., Shreffler, J., Schoster, B., Callahan, L.F., 2010. Associations of perceived neighborhood environment on health status outcomes in persons with arthritis. Arthritis Care Res. 62, 1602-1611.

Mason, W.A., Kosterman, R., Haggerty, K.P., et al., 2009. Gender moderation and social developmental mediation of the effect of a family-focused substance use preventive intervention on young adult alcohol abuse. Addict. Behav. 34, 599-605.

McNeill, L.H., Kreuter, M.W., Subramanian, S.V., 2006. Social environment and physical activity: a review of concepts and evidence. Soc. Sci. Med. 63, 1011-1022.

Moore, S., Daniel, M., Bockenholt, U., et al., 2010. Associations among socioeconomic status, perceived neighborhood control, perceived individual control, and selfreported health. J. Community Psychol. 38, 729-741.

Muñoz, R.F., Ying, Y.-W., 2002. The Prevention of Depression: Research and Practice. JHU Press.

Neogi, T., Zhang, Y., 2013. Epidemiology of osteoarthritis. Rheum. Dis. Clin. N. Am. 39, $1-19$.

O'Connor, G., Fitzpatrick, K., 2017. Do place and time make a difference? Examining quality of life among homeless persons in Northwest Arkansas and birmingham. Community Ment. Health J. 53, 334-339.

Pedhazur, E., 1997. Multiple Regression in Behavioral Research: Explanation and Prediction. Thomson Learning. Inc, United States.

Petersen, M.L., Sinisi, S.E., van der Laan, M.J., 2006. Estimation of direct causal effects. Epidemiology 276-284.

Pew Research Center. In a recovering market, homeownership rates are down sharply for blacks, young adults. http://www.pewsocialtrends.org/2016/12/15/in-a-reco 
vering-market-homeownership-rates-are-down-sharply-for-blacks-young-adults/. Retrieved October 18, 2017, from.

Preacher, K.J., Zhang, Z., Zyphur, M.J., 2011. Alternative methods for assessing mediation in multilevel data: the advantages of multilevel SEM. Struct. Equ. Model $18,161-182$.

Prieto-Flores, M.E., Fernandez-Mayoralas, G., Forjaz, M.J., Rojo-Perez, F., MartinezMartin, P., 2011. Residential satisfaction, sense of belonging and loneliness among older adults living in the community and in care facilities. Health Place 17, $1183-1190$.

Radloff, L.S., 1991. The use of the center for epidemiologic studies depression scale in adolescents and young adults. J. Youth Adolesc. 20, 149-166.

Richardson, R., Westley, T., Gariepy, G., Austin, N., Nandi, A., 2015. Neighborhood socioeconomic conditions and depression: a systematic review and meta-analysis. Soc. Psychiatry Psychiatr. Epidemiol. 50, 1641-1656.

Sallis, J.F., Bowles, H.R., Bauman, A., et al., 2009. Neighborhood environments and physical activity among adults in 11 countries. Am. J. Prev. Med. 36, 484-490.

Sampson, R.J., Raudenbush, S.W., Earls, F., 1997. Neighborhoods and violent crime: a multilevel study of collective efficacy. Science 277, 918-924.

Sawatzky, R., Ratner, P.A., Johnson, J.L., Kopec, J.A., Zumbo, B.D., 2010. Self-reported physical and mental health status and quality of life in adolescents: a latent variable mediation model. Health Qual. Life Outcomes 8, 17.

Shaw, C.R., McKay, H.D., 1996. Juvenile Delinquency and Urban Areas, vol. 19421, p. 19692. Chicago.

Singh, G.K., Siahpush, M., 2014. Widening rural-urban disparities in all-cause mortality and mortality from major causes of death in the USA, 1969-2009. J. Urban Health 91, 272-292.

Skinner, E.A., Zimmer-Gembeck, M.J., 2011. Perceived Control And The Development Of Coping. The Oxford Handbook Of Stress, Health, And Coping, pp. 35-59.

Steiger, J.H., Lind, J.C., 1980. Statistically Based Tests for the Number of Common Factors. annual meeting of the Psychometric Society, Iowa City, IA.

Strawbridge, W.J., Deleger, S., Roberts, R.E., Kaplan, G.A., 2002. Physical activity reduces the risk of subsequent depression for older adults. Am. J. Epidemiol. 156, 328-334.
Taylor, A.W., Chittleborough, C., Gill, T.K., et al., 2012. Relationship of social factors including trust, control over life decisions, problems with transport and safety, to psychological distress in the community. Soc. Psychiatry Psychiatr. Epidemiol. 47, 465-473.

Taylor, A.W., Kelly, G., Dal Grande, E., et al., 2017. Population levels of wellbeing and the association with social capital. BMC Psychol 5.

Truong, K.D., Ma, S., 2006. A systematic review of relations between neighborhoods and mental health. J. Ment. Health Policy Econ. 9, 137-154.

Tucker, L.R., Lewis, C., 1973. A reliability coefficient for maximum likelihood factor analysis. Psychometrika 38, 1-10.

Uchino, B.N., 2006. Social support and health: a review of physiological processes potentially underlying links to disease outcomes. J. Behav. Med. 29, 377-387.

U.S. Census Bureau, 2010. Census Urban and Rural Classification and Urban Area Criteria. Retrieved October 17, 2017, from. https://www.census.gov/geo/refer ence/ua/urban-rural-2010.html.

U.S. Census Bureau. Projections of the size and composition of the u.s. population: 2014 to 2060. Retrieved Dec 18, 2017, from. https://www.census.gov/content/dam/Cens us/library/publications/2015/demo/p25-1143.pdf.

U.S. Census Bureau. Geographic terms and concepts - block groups. Retrieved Nov 28 2017, from. https://www.census.gov/geo/reference/gtc/gtc_bg.html.

VanderWeele, T.J., 2016. A unification of mediation and interaction: a 4-way decomposition (Vol 25, pg 749, 2014). Epidemiology 27. E36-E36.

Weden, M.M., Carpiano, R.M., Robert, S.A., 2008. Subjective and objective neighborhood characteristics and adult health. Soc. Sci. Med. 66, 1256-1270.

Weissman, M.M., Sholomskas, D., Pottenger, M., Prusoff, B.A., Locke, B.Z., 1977. Assessing depressive symptoms in five psychiatric populations: a validation study. Am. J. Epidemiol. 106, 203-214.

Wiles, J.L., Leibing, A., Guberman, N., Reeve, J., Allen, R.E.S., 2012. The meaning of "aging in place" to older people. Gerontol. 52, 357-366.

Yen, I.H., Michael, Y.L., Perdue, L., 2009. Neighborhood environment in studies of health of older adults: a systematic review. Am. J. Prev. Med. 37, 455-463. 